\title{
Die höchste Gottheit bei den kulturarmen Völkern.
}

\author{
Von
}

\author{
K. Th. Preub.
}

Zum Wesen der Religion sind nach der üblichen Auffassung zwei Dinge notwendig, die ohne einander nicht bestehen können, nämlich Götter im.weitesten Sinne einerseits und Kult andererseits. Schon ein Zauberakt, der Unheil verscheuchen oder einen Naturgegenstand beeinflussen will, zeigt diese beiden Seiten der Religion auf, indem das mehr oder weniger persönlich gedachte Naturding die Gottheit, der Zauber den Kult darstellt. Gehen wir vollends vom Dämon, von der Gottheit aus, so ist es einleuchtend, daß man eine solche Bezeichnung gar nicht anwenden würde, wenn der Gott nicht irgendwie in das Leben eingriffe und durch kultische Handlungen bestimmt werden könnte. Dann würden wir eher von mythischen Persönlichkeiten sprechen, die dem Drange nach Erkenntnis entsprungen sind, während die Religion von wunschhaften Erregungen ausgegangen erscheint, die sich nicht ohne weiteres ausgleichen ließen.

Nun gibt es aber eine Menge zauberhafter Handlungen und Meidungen, die ganz im allgemeinen Gelingen erzielen und Unglück verhüten sollen, ohne daß ein dämonisches Wesen als Vermittler oder Ausgangspunkt dafür gedacht ist. Dahin gehören z. B. viele aus praktischen Gewohnheiten entstandene Gebräuche.

Wenn wir also den Kult in manchen zauberhaften, abergläubischen Handlungen gewissermaßen ohne einen Gott oder Dämon tinden, so gibt es umgekehrt auch göttliche Wesen, die wir nicht von der Religion trennen können, die also eine solche Bezeichnung verdienen und doch zum Teil keinen Kult genießen. Das sind die Heilbringer und die höchsten Götter, die man in ihrem Wesen voneinander unterscheiden muß, obwohl sie manche Ähnlichkeiten haben. Die Entdeckung dieser Wesen schneite so unvermittelt in die vorgefaßten entwickelungstheoretischen Auffassungen der Völkerkunde vom Niederen zum Höheren hinein, daß diese sich jahrzehntelang gestrüubt hat, sich mit ihnen zu befassen, und sie erst jüngst fest ins Auge gefaßt hat ${ }^{1}$ ). Nachdem der Gedanke an

1) Andrew Lang, The Making of Religion. London 1898. - Ehrenreich, Götter und Heilbringer. Zeitschr. f. Ethnol. 1906, S. 536-610. - Ehrenreich, Die allgemeine Mythologie. Leipzig 1910. - P.W. Schmidt, Der Ursprung der Gottesidee I. Münster i. W. 1912. - Nathan Söderblom, Das Werden des Gottesglaubens. Leipzig 1916. 
christlichen Einfluß auf die Gestaltung der höchsten Götter aufgegeben ist, kann man es verstehen, daß sie wegen ihrer Eigenschaften von manohen Forschern idealisiert oder als Urmonotheismus und eine Art Uroffenbarung aufgefaßt sind. Für diejenigen aber, die solche Wesen mit dem bisher Erforschten in Einklang zu bringen suchen, ergibt sich eine gewisse Umwälzung ihrer Anschauungen, weil nunmehr feststeht, daß auch auf niederer Stufe neben mehr oder weniger unverständlichem Zauberkult erhabene, einer Religion in unserem Sinne würdige Gedanken vorkommen. Bevor aber auf Einzelheiten eingegangen werden kann, müssen wir die Stellung der Heilbringer und höchsten Götter als überhaupt zur Religion gehörig kennzeichnen, da sie wegen ihrer Kultlosigkeit davon ausgeschlossen werden könnten.

Heilbringer pflegt man die menschlichen oder tierischen Persönlichkeiten zu nennen, von denen erzählt wird, daß sie manche Einrichtungen in der schon bestehenden Welt geschaffen, insbesondere auch den Menschen soziale Ordnung, Sitten und Zeremonien gegeben haben. Obwohl sich solche Taten an den Namen von personifizierten Naturdingen knüpfen können, die auch einen Kult genießen, sind es doch meist mythische Gestalten oder Ahnen, die keinen Einfluß mehr auf das Leben ausüben, verschollen oder gestorben sind, von denen also nichts als der Bericht ihrer Taten übrig geblieben ist. Es hieße, die religiöse Berleutung solcher Heilbringer verkennen, wollte man sie nur als Erzeugnis des wissensdurstigen Geistes auffassen, der eine Erklärung verlangt. Schon die Schöpfung der Welt und die Einfügung von Flüssen, Bergen, der Sonnenbahn u. dgl. m. in die Welt bedeutet für den menschlichen Geist die Gewähr dauernden Bestehens der betreffenden Dinge, und mehr noch ist der Mensch darauf aus, eine Gewähr für die Wirksamkeit seiner Zeremonien zu haben. Die Erzählung vom Heilbringer macht die Gebräuche heilig und läßt an ihnen nicht deuteln. Seine übermenschlichen Taten, die er daneben vollführt hat, stellen auch die Gebräuche als übermensehlich und der gewöhnlichen Vernunft unzugänglich hin. Die Menschen, die sie ausführen, erscheinen dann nicht mehr als sinnlose Zauberer, die so töricht sind zu glauben, daß sie mit irgendwelehen schwächlichen Mitteln das Naturgeschehen meistern können, sondern als demütige gläubige Jünger eines großen Meisters, die unter ungeheuern Anstiengungen und Selbstpeinigungen sich seiner würdig beweisen wollen, soviel in ihren schwachen Kräften liegt.

Der Heilbringer hat auch die bedeutungsvolle Eigenschaft, daß er als Freund und Stammesgenosse gegenüber der im Grunde feindlichen menschlichen oder dämonischen Umwelt erscheint. Er ist daher, wenn er auch nicht mehr existiert, eine durchaus religiöse Figur. Der ihm gewidmete Kult ist die Erzählung, mitunter auch Darstellung seiner 
Taten. Wie Erzählungen ähnlicher erfolgreicher Verrichtungen, Heilungen, Siege u. dgl. eine zauberische Gewähr für das Gelingen im gegenwärtigen Fall bieten, so stärkt der Heilbringer den Glauben an die Zeremonien, die einen Erfolg direkt oder auf dem Umwege über einen Dämon bezwecken, in wunderbarer Weise, Ja, man muß sich fragen, inwieweit solche Heilbringergestalten schon bei der Schaffung von zauberischen Kultakten mitgewirkt haben, indem nicht die Erregung und der sehnsüchtige Wunsch verbunden mit der Denkweise allein den Glauben an Gelingen gezeitigt haben, sondern auch das Vorbild des überragenden Heilbringers. Bekanntlich haben die Kulturarmen so gut wie gar keine Geschichte. Sie gehen vielmehr in ihren Überlieferungen sofort auf Weltschöpfung, Entstehung der Menschen oder ihrer Herkunft aus dem Schoß der Erde, auf die Sintflut und andere große Katastrophen, Gestaltung der Erdoberfläche und übermenschliche Taten von Wesen zurück, die öfters als Verkörperung von Naturgewalten, Gestirnen usw. nachgewiesen werden können. Alles andere interessiert sie gar nicht. Dürfen wir da nicht ganz naiv sagen: Die Umwelt hat eben einen entsprechenden Eindruck auf sie gemacht, und die Möglichkeiten des Wirkens erscheinen ihnen von vorneherein ganz anders weit gesteckt wie uns, zumal ihre eigenen Vorfahren oder ihnen nahestehende Gestalten dabei mitgewirkt haben? Heute, wo wir Jahrtausende von Geschichte übersehen und wirkliche und eingebildete Welt wenigstens begrifflich sehr wohl zu unterscheiden verstehen, können wir uns gar nicht in die Spannung hineinversetzen, mit der die Kulturarmen solche Mythen aufnehmen, und nur unsere, dem wirklichen Leben noch fernstehenden Kleinen haben ihre Teilnahme für ähnliche, freilich stark vermenschlichte Erzählungen bewahrt.

Äußerlich unterscheidet sich die höchste Gottheit nicht sehr vom Heilbringer, denn auch sie hat den Menschen den Kult gegeben, und ihre Taten sind nur größer, nämlich die Welt- und Menschenschöpfung. Aber ihr Ursprung und ihre Bedeutung sind ganz andere. Sie ist nicht gestorben oder verschwunden wie der Heilbringer, sondern befindet sich meist im Himmel, ihre Macht über die ganze Welt ist nicht geschwunden, aber sie kümmert sich nicht um die Menschen, weshalb diese ihr auch keinen Kult widmen oder sie nur durch Gedenken und gelegentliche Anrufungen ehren, jedenfalls in ganz anderer Weise kultisch behandeln wie ihre übrigen Götter und Dämonen, denen der ganze Wust der Zauberkulte gewidmet ist. Wo aber auch ihr solcher Kult zuteil wird, da geschieht es, weil sie mit irgendeinem Naturding, besonders der Sonne identifiziert worden ist. Dabei gilt sie als gütig, gerecht und ewig, ganz im Gegensatz zu den Dämonen. Im Grunde geht also alle Macht, auch die der Dämonen, von ihr aus, obwohl sie diese in ihren Wirkungsbezirken gewähren läßt. Sie ist demnach auch der oberste 
Schamane, hat aber auch hierin ihre Fähigkeiten dem irdischen Schamanen übergeben.

Wie bewerten wir nun diese Gestalt in religiöser Beziehung, ohne da $B$ den sonstigen Tatsachen der Völkerkunde Gewalt angetan wird? Alle Forscher, die sich bewußt mit der höchsten Gottheit beschäftigt haben, sind heute darüber einig, daß sie nicht eine Entwickelungsspitze, ein gedanklicher Schlußstein für den Bau des Göttertempels ist, sondern ein frühes religiöses Frzeugnis sein kann. Hier allerdings trennt sich bereits die Partei ab, die den Gott nach ,exakt geschichtlicher Methode“ für die heutigen Urvölker, angeblich die Pygmäenstämme, in Anspruch nehmen will und dadurch mit $P$. W. Schmidt zu Urmonotheismus und Uroffenbarung gelangt. In der Tat gibt es Fälle, wo wir keine andern Nachrichten haben als die über das Bestehen eines solchen Eingottes, aber meist sind die Nachrichten nicht erschöpfend, auch nicht aus Texten genommen, die man hierfür nicht entbehren kann, und vor allem kommt die Gottheit in entschiedener Ausprägung auch bei andern als den sog. Urvölkern vor, sowohl als eine Art Eingott wie auch an der Spitze der Götterhierarchie. In Afrika z. B. gibt es Nachrichten über diesen Gott bei den Pygmäen so gut wie gar nicht, wie ich einem bisher ungedruckten Vortrage von B. Ankermann in dem Ethnologischen Colloquium in Berlin entnehme, während er sonst dort sehr verbreitet ist, und in Amerika erwähnen ihn neuere Nachrichten (s. weiter unten) unter besonders tiefstehenden Stämmen nur bei den Botokuden, obwohl er dort ein sehr bedeutsamer Bestandteil einiger Religionen ist. Wir müssen demnach damit rechnen, daß die seelische Anlage, die solche Gottheiten schafft und erhält, zeitlich und örtlich fruchtbar bleibt, ohne daß man mit Andrew Lang von einer Degeneration reden darf.

Die religiöse Bedeutung des höchsten Gottes für das Werden des Gottesglaubens hat Söderblom sehr einleuchtend dargelegt, hat auch seine Sonderstellung inmitten der übrigen Götter und Dämonen erkannt, hat sich aber den Weg der Erklärung, wie der Gott unter die sonstigen religiösen Vorstellungen einzugliedern ist, dadurch versperrt, daß er ihn außerhalb der Welt stellt und ihn rein kausal den Urheber nennt, wie er auch schon für $A$. Lang der bloße Macher war. Wo der Gott wohnt, ist nach Söderblom gleichgültig. Er habe seine grundlegenden Eigenschaften nicht aus dem Himmel, sondern aus seinem Beruf, Urheber von Wesen, Dingen, Einrichtungen und Zeremonien zu sein. „Die Beziehung zum Himmel müssen wir ebenso wie die andern Naturbeziehungen zu Gestirnen, Donner usw. bei den Urhebern als sekundär erklären ${ }^{\text {sc }}$ (S. 162).

Demgegenüber muß ich betonen, daß ein solch abstrakter Urheber der Gedankenwelt der kulturarmen Völker fremd ist. Der Dämon oder Gott pflegt überhaupt, falls er nicht ein Verstorbener ist, immer ein Naturding zu verkörpern, nach dessen Wesen hauptsächlich sein Wirkungg- 
bereich begrenzt ist. Noch der herabfallende Regentropfen ist der Regengott und jedes Maiskorn der Gott der Vegetation. Nur wo sich die Wirkung aufdrängt, ohne daß der Urheber sinnlich wahrnehmbar ist wie bei Krankheiten, oder als Beschützer von Tätigkeiten, wird der betreffende Gott, - aber auch dann nur selten -, aus dem Nichts erfunden, häufiger aber die Wirkung schon vorhandenen Naturdämonen oder auch Verstorbenen zugeschrieben. Für einen Himmelsgott, der die ganze Welt beherrscht und schafft, kommt also nur in Betracht, daß er eine Verkörperung der ganzen Welt darstellt. Der menschlichen Vorstellung entsprechend wird dann der hervorragendste, beherrschende Teil des Weltalls, der Himmel, als sein Wohnsitz betrachtet.

Nur in der Voraussetzung, daß der höchste Gott die ganze Welt personifiziert, ist seine Stellung in der Religion verständlich. Nur in diesem Fall hat er religiöse Bedeutung, auch wenn er keinen Kult genießt, denn seine bloße Exxistenz ist die Gewähr für das Bestehen der Welt. Er darf nicht verschwinden und sterben wie der Heilbringer, denn sonst besteht auch die Welt nicht mehr, die er verkörpert. Es ist ein Widerspruch, wenn Ehrenreich ihn die Welt verkörpern läßt, dann aber fortfährt: Er ist jedoch völlig mythisch. Er genießt freilich keinen Kult, ganz wie irgendeine mythische Gestalt, die nur in der Utberlieferung vorhanden, in der Religion aber bedeutungslos ist, aber er ist doch da, und man gedenkt seiner als mächtigen gütigen und gerechten Herrschers. Er erhält auch die Welt, indem ihm öfters zugeschrieben wird, daß er den Tod sendet, worauf Söderblom aufmerksam macht, und daß zuweilen auch die Geburt der Kinder durch seine Mitwirkung erfolgt.

Seine Hauptfürsorge für die Welt und für die Menschen drückt sich aber darin aus, daB er den Menschen den Kult gegeben hat, wodurch diese in den Stand gesetzt werden, die Welt zu beherrschen und alle Verhältnisse im All zu regeln. Während ihm gegenüber der Heilbringer in der Einführung der Zeremonien zum bloßen Vermittler herabsinkt, machen diese das Wesen des höchsten Gottes aus. Sie sind ein Bestandteil von ihm selbst und damit der Welt, die ja auch nur den Gott selbst vorstellt, gleichgesetzt. Das Wort, wie der Kult manchmal genannt wird, bildet daher nach einer Angabe ebenso wie die Welt das Ding, aus dem. der Gott seinen Ursprung nimmt. Es ist in dem Falle früher da als er selbst. Aus dem Wort kann er ohne Eltern geboren werden. Welt und Wort unterscheiden sich dadurch, daß erstere die passive Seite der Gottheit darstellt, letzteres die aktive, die er nicht von sich aus ausübt, sondern den Menschen überlassen hat. Deshalb ist er auch selbst vom Kult ausgeschlossen, sofern er nicht mit Teilen der Weit identifiziert wird. Da die Macht, die Welt zu regieren, eigentlich bei den Menschen liegt, so ist es nur folgerichtig, daß der Gott selbst öfters der erste Mensch genannt wird, indem er in dieser Beziehung wicder mit dem Heilbringer 
zusammenfällt. Auch liegt in der Bezeichnung erster Mensch eine Art Pantheismus, da der Gott den von ihm geschaffenen Menschen wie die ganze Welt verkörpert.

Die Güte und Gerechtigkeit des Gottes erklärt sich daraus, daß ihm das Bestehen der Welt und der Menschheit zu danken ist, sowohl in bezug auf die Schöpfung wie bezüglich der Erhaltung. Die kulturarmen Völker sind selten so angekränkelt, daß sie nicht Freude am Dasein haben. Außerdem haben sie die glückliche Anlage, daß jeder Stamm sich als den Mittelpunkt der Welt und der Menschheit fühlt und demgemäß der Gott gerade am wohlwollendsten zu ihnen erscheint. Und wenn es ihnen schlecht geht so ist nicht der Gott dafür verantwortlich, sondern sie selbst, weil sie in ihrer Unvollkommenheit das "Wort" nicht richtig handhaben und deshalb die feindliche Umwelt nicht bemeistern. Der Gegensatz zwischen der freundlichen Gestalt des höchsten Gottes und der im Grunde meist feindlichen und deshalb der Kultbehandlung bedürftigen Umgebung tritt ebenso wie beim Heilbringer deutlich hervor.

Man sieht, ein richtiger Gott ist die höchste Gottheit eigentlich nicht. Sie ist vielmehr nur eine Ergänzung zu den Zauberkulten, wie auch der Heilbringer eine dazu war, und deshalb ist nicht eine besonders philosophische, den Kulturarmen unerreichbare Idee zu der Konzeption einer solchen Gestalt notwendig. Sie erscheint nur fremdartig, weil die Ethnologie gewohnt ist, mit vorgefaßten Meinungen einer Entwickelung der Menschheit aus ganz rohen Anfängen zu arbeiten, und glücklich ist, wenn sie möglichst Brutales überall findet. Natürlich ist sie daher geneigt, alles andere zu übersehen und für unmöglich zu halten, und das um so mehr, weil nur das Aufschreiben von Überlieferungen in den Sprachen der Kulturarmen einen Weg in ihre Anschauungen öffnet, nicht aber das bloße Besehen ihres Treibens und das Sammeln ihrer Kulturgüter. Aber auch, wenn wir mehr Textmaterial hätten, ist die Psyche der Kulturarmen sehr schwer zu verstehen, weil eine historische Aufeinanderfolge trotz aller Versicherungen exakt historischer Methode der Untersuchung nur gewaltsam zu konstruieren ist. Das gilt auch von unserm höchsten Gotte.

Untersuchen wir nämlich die einzelnen Fälle, so finden sich eben nicht solch reinliche Unterscheidungen, wie sie hier vorgebracht sind, sondern es ist meist eine, wenn auch z. T. nur geringe Mischung mit den gewöhnlichen Göttern eingetreten. Das hat zu der Meinung geführt, er unterscheide sich von diesen nur durch eine größere Höhe der Auffassung, weshalb die Menschheit seit der Urzeit in religiöser Beziehung durch Überhandnahme von Zauber und Dämonen rückwärts gegangen sei (A. Lang, P.W. Schmidt). Indessen wird dadurch seine Kultlosigkeit und die Verleihung des Kults an die Menschen nicht erklärt, ganz abgesehen davon, daß unsere Kenntnis von ihm bei den sog. Urvölkern noch 
sehr gering ist und andererseits der Gott in derselben Gestalt auch sonst bei den fortgeschritteneren Kulturarmen erscheint. Auch ist es einleuchtend, daß eine fruchtbare Verbindung dieser Gottheit mit Natur. dämonen bzw. mit einem vereinzelten Naturding erfolgen kann, wodurch der höchste Gott zwar in das Wesen der Dämonen herabgezogen, zugleich aber eine freundliche, verehrte und mit Vertrauen aufgenommene Gestalt etwa unter der Bezeichnung Vater, also ein wirklicher Gott in unserem Sinne entstehen kann. Dieselbe fruchtbare Verbindung kann durch den Zusammentritt eines Heilbringers mit einem Dämon zu einer Göttergestalt stattfinden, die diese Bezeichnung mit Recht trägt。

Wir kommen jetzt zu den entsprechenden Untersuchungen bei ein. zelnen amerikanischen Stämmen, für deren Verständnis die vorhergehenden allgemeinen, auch die übrige Literatur berücksichtigenden Bemerkungen notwendig waren. Da in dieser Amerika am wenigsten berücksichtigt ist, so glaube ich die Frage des höchsten Gottes durch diese Beispiele fördern zu können. Das Material dazu bilden eingehende auf Texte gegründete Untersuchungen, die von mir auf meinen Rueisen aufgenommen und z. T. bereits veröffentlicht oder im Druck sind. Nur für die alten Mexikaner liegen Texte der alten spanischen Schriftsteller zugrunde, während das Beispiel der Botokuden auf einer neueren Quelle ohne Texte beruht, doch erschien es mir deshalb von Belang, weil die Botokuden als besonders ursprünglich gelten. Die Reihenfolge ist lediglich für das Verständnis ausgewählt, damit einfachere den schwerer verständlichen Formen vorausgehen. Nur die Botokuden sollen als weniger zuverlässiges und vielleicht unvollständiges Beispiel zuletat folgen. Wir behandeln demnach in einer Reihe die Kágaba, Uitoto, Cora, alten Mexikaner und Botokuden.

\section{Die Kágaba ${ }^{1}$ ).}

Der Fall der Kágaba auf dem Nordabhang der Sierra Nevada de Santa Marta in Kolumbien, der Sprachverwandten der alten Chibcha auf der Hochebene von Bogotá, gestaltet sich besonders einfach, weil wie kaum bei einem andern Volke die drei Bestandteile der religösen Mächte, 1. die höchste Gottheit, 2. die Heilbringer oder Vermittler und 3. die Dämonen scharf in ihrer Natur gesondert und charakterisiert sind. Erstere ist weiblich und heißt Mutter des Feuers ( $Q$ auteóvañ) oder Mutter des Gesanges (Š́íalaneumáñ), hat aber seltener auch noch andere, nicht zu übersetzende Namen. Ihre weibliche Natur erklärt sich wohl aus der früheren Bedeutung, die die Frau unter diesem vom Ackerbau

1) Preuß 3 , Forschungsreise zn den Kágabaindianern. Anthropos $X I V-X V$, 1919-1920, S. 314-404. 1040-1079 (mit mehreren, noch nicht gedruckten Fortsetzungen). Das Ganze soll später in Buchform im Verlage des Anthropos erscheinen. 
lebenden Volke hatte. Obwohl jetzt Vaterrecht in freier Familienverfassung herrscht, zieht der Mann doch noch in das Dorf der Frau, wenn er ausnahmsweise nicht im eigenen Dorfbezirk heiratet. Auch gibt es neben den vier bis fünf Urahnen (Heilbringern), auf die alle Familien zurückgehen, und von denen alle Menschen abstammen, nebenbei und nicht ganz feststehend auch vier Frauengeschlechter, abgeleitet von Schwestern der Urahnen oder anderer Vorfahren. Es besteht die Tendenz, die Gottheit als Frau eines der vier Urahnen oder Heilbringer hinzustellen, und in einem Dorfe, aus dem meine Nachrichten nicht stammen, scheint schon die Schaffung eines Urelternpaares mit einem der männlichen Urahnen als Haupt durchgeführt zu sein. Indessen ist aus den Texten des Dorfes Palomino klar ersichtlich, da $B$ die weibliche höchste Gottheit das Ursprüngliche ist. Wir können daraus und aus anderen Beispielen lernen, daß je nach der Bedeutung des Mannes oder der Frau in der sozialen Gemeinschaft die höchste Gottheit männlich oder weiblich sein kann, ohne daß ihr Wesen sich dadurch oder durch das Vorhandensein oder Nichtvorhandensein einer Familie (Frau bzw. Mann und Kinder) besonders ändert. Vor allem erscheint es nicht erforderlich, daß für das Zustandekommen der höchsten Gottheit ein starkes Häuptlingstum in der betreffenden sozialen Gemeinschaft notwendig ist. Bescheidene Anfänge dazu, wie sie allenthalben schon in der Familie vorhanden sind, können genügen, denn die sich in der Natur offenbarenden ungleichmäßigen Kräfte, die den Dämonen oder Gottheiten zugrunde liegen, haben an den irdischen Zuständen immer treffende Parallelen.

Die höchste Gottheit der Kágaba erscheint als Allmutter, aus deren Schoß alle Naturdinge d. h. Dämonen und die Menschen hervorgegangen sind. Folgerichtig ist von einer Weltschöpfung nicht die Rede, da wir sie selbst als Verkörperung der. Welt ansehen müssen. Überhaupt scheint eine Auffassung von den Einzelheiten der Weltschöpfung erst zu entstehen, wenn die höchste Gottheit außer der Welt auch ein bestimmtes Naturding verkörpert, indem letzteres dann die Grundlage für Ideen der Erschaffung liefert. Betont wird ihre Eigensehaft als Mutter des Feuers, der Sonne und der Milchstraße neben vielen anderen besonders erwähnten Naturdingen. Daraus geht hervor, daß sie nicht nur die Erde, sondern das All verkörpert. Von der Sonne heißt es auch ausdrücklich, daß sie sie geschaffen habe. Die Feuereigenschaft, die in ihrem häufigsten Namen „Mutter des Feuers" liegt, ist demnach von dem. wesentlichsten Teil der Welt, die sie verkörpert, genommen. Einen besondern Aufenthaltsort hat sie nicht, auch ist sie nicht etwa zum Monde in Beziehung gesetzt. Sie ist tatsächlich über allen Dingen.

Die prägnante Schilderung ihres Wesens in einem Texte verdient hier wörtlich angeführt zu werden: 
„Die Mutter des Gesanges, die Mutter unseres ganzen Samens, gebar uns im Anfang. Sie ist also die Mutter aller Arten von Menschen und die Mutter von allen Stämmen. Sie ist die Mutter der Donner, die Mutter der Flüsse, die Mutter der Bäume und aller Arten von Dingen. Sie ist die Mutter der Welt und der älteren Brüder Steine ${ }^{1}$ ). Sie ist die Mutter der Feldfrüchte und die Mutter aller Dinge. Sie ist die Mutter der jüngeren $\mathrm{Brüder}^{2}$ ) Franzosen und der Fremden. Sie ist die Mutter der Tanzgeräte und aller Tempel und ist die einzige Mutter, die wir haben. Sie allein ist die Mutter des Feuers, der Sonne und der Milchstraße. Die Mutter selbst war es, die zu taufen begann, sie selbst händigte die Kalkdose (zum Kokaessen) ein. Sie ist die Mutter des Regens, die einzige, die wir haben. Diese Mutter des Gesanges ist die Mutter der Dinge, sie allein. Und uns hat die Mutter ein Andenken in. allen Tempeln hinterlassen. Zusammen mit ihren Söhnen Seižánkua, Sintánà, Aluañuiko und Kulťsavitabáuya (den Urahnen und Heilbringern) hinterlieB sie als Andenken Gesänge und Tänze. Das haben die Priester, Väter und älteren Brüder berichtet."

Den schöpferischen Teil des Wesens der Allmutter aus diesem Bericht haben wir bereits vorher hervorgehoben. Was sonst noch darin vorkommt, bezieht sich auf die andere einer höchsten Gottheit notwendig zukommende Seite als Quelle alles Kults. Bedeutsam wird darin weniger betont, daß sie dieses und jenes davon eingeführt habe, als vielmehr, daß sie die Mutter der Tanzgeräte, der Tempel und des Gesanges ist, d. h. daß auch diese Dinge des Kultus - und unter Gesang sind immer sämtliche Zeremonien gegenüber den Dämonen verstanden - von ihr emaniert sind. Auch aus andern Stellen der Texte geht hervor, daß sie besonders für die priesterliche Tätigkeit gesorgt hat, sie hat auch gewisse, für den Kult äußerst wichtige, als Fastenspeise dienende Tiere, den Wels und den Krebs, unter ihrer Obhut, und sie hat die Taufe eingeführt, deren $Z$ week darin besteht, den Täufling durch eine Reihe von Zeremonien zeugungsfähig zu machen und den Erfordernissen des Lebens anzupassen. In dieser kultlichen Fürsorge ist deutlich die Erhaltung des Menschen und - da die Priester durch ihre Zeremonien auch die Natur beherrschen, z. B. sogar den Einsturz der vier Richtungen des Himmels und der Berge verhindern - auch die Erhaltung der Welt zum Ausdruck gebracht. In dem Dorfe, wo statt der Allmutter schon ein Urpaar, d. h. die Herrschaft eines männlichen höchsten Gottes aufgekommen ist, wurde auch direkt berichtet, ohne die beiden würde die Welt untergehen.

Bei alledem gehört es, wie im allgemeinen Teil auseinandergesetzt ist, zur Gestaltung einer höchsten Gottheit, da $\beta$ ihre Fürsorge durchaus

1) Die ersten Generationen der Kágaba waren Steinmenschen.

2) Die Kágaba nennen sich ältere Brüder im Gegensatz zu allen anderen Menschen, die sie als jüngere Brüder*bezeichnen. 
nicht durch den Kult immer wieder erzwungen wird, sondern in durchdachten Anordnungen und Einrichtungen von Anbeginn an liegt. Wie leicht verständlich wäre es z. B., daß man der Allmutter als Mutter der Donner, Flüsse, Seen, des Regens, der Sonne usw. immer direkt zusetzte, wenn man Regen, Trockenzeit usw. haben will. Man tut es ausgesprochen aus dem Grunde nicht, weil man von ihr die Kultmittel hat, diese Naturwesen zu beeinflussen. Eș ist ohne weiteres klar, daß bei dem lebendigen Glauben an die Allmutter diese Zeremonien in ihr ihre besondere Stütze haben, sie als Ergänzung dazu notwendig ist. Es zeugt ferner für die feste Verankerung dieses religiösen Grundgedankens von der Allmutter in der menschlichen Psyche, daß sie sich durchaus nicht mit den Naturdämonen vermischt hat. Sie ist und bleibt im wesentlichen kultlos. Daraus den Schluß zu ziehen, daß sie früher eine wirkliche Gottheit mit Verehrung durch Gebet, Anruf und Opfer gewesen und durch Aufkommen der Zauberkulte an die Naturdämonen von ihrer überragenden Stellung in der lebendigen Verehrung des Volks verdrängt worden ist, ist offenbar ebenso verfehlt, wie der andere, sie habe sich aus den Naturdämonen entwickelt. Man muß also mit ihr als einem besonderen Bestandteil des religiösen Glaubens rechnen und ihr einen Dauerwert zuerkennen, also auch Ähnliches in anderen Religionen auszusondern trachten.

Die nun anzuführenden Spuren eines ihr gewidmeten Kults sind demnach ursprünglich als ihrem Wesen nicht zugehörig zu betruchten. Ihr müßte eigentlich nur bloßes Gedenken zukommen, und das findet sich auch außer der ihr Wesen schildernden, oben wiedergegebenen Erzählung in zwei Kultgesängen an die Naturdämonen.

„Wenn man die Feldfrüchte (durch Zaubersteinchen) zu schützen begann, sangen die Priester diesen Gesang, damit die Bohnen nicht verwelken und die Blätter der Kartoffeln und des Maises nicht verbrennen. Man setzte die Sonnen-Seižuakukui-Maske auf, vereinigte die Zaubersteinchen auf den Äckern und trug sie nach allen Feldern. Darauf dachte man an die alleinige Mutter der Feldfrüchte, an die Mutter aller Dinge. Das haben die Väter erzählt."

Indem man also zauberischen Schutz gegen den Sonnendämon herstellt, denkt man schließlich an die Allmutter, ein Ausdruck, der in bezug auf den Kult gegenüber den Dämonen nicht gebraucht wird. In dem andern Gesang ist aber statt des Gedenkens ein den Dämonen gegenüber angewendeter Ausdruck. ,anreden“ und „,singen" gebraucht, was die Beeinflussung durch zauberischen Kult (Tanz usw.) in sich schließt. Es wird in dem Gesang von einem Priester-Vorfahren erzählt:

„...Er begann die Feldfrüchte (durch Zaubersteinchen) zu schützen, den Regen anzureden und die Trockenzeit zu machen, 
gebrauchte die Festgeräte, tanzte und baute Tempel $\left.{ }^{1}\right)$. Dann redete er die Mutter an, die Mutter der Tempel, der Welt und aller Dinge und sang ihr..."

Trotz dieser falschen Ausdrücke ,anreden" und ,singen" sieht man aus der Gegenüberstellung der dämonischen Kulttätigkeit und der schließlichen Wendung an die Allmutter, daß nur ein Gedenken gemeint ist, und daß man nichts direkt von ihr haben will.

Dementsprechend erhält man von den Indianern, wenn man sie nach dem Grund einer Zeremonie fragt, manchmal die zutreffende Antwort „damit es die Allmutter sieht". Darin liegt die ständige Überwachung der Zeremonien zur Regelung des Weltgeschehens ausgedrückt, ohne daß sie aber im einzelnen eingreift. Es ist auch hier vielmehr nur das ständige Gedenken daran zum Ausdruck gebracht, daß die Zeremonien von ihr stammen. Dagegen ist wiederum der falsche Ausdruck , anreden “ in einer Erzählung von der Tätigkeit eines mythischen Heilbringers angewandt: ,Um die Allmutter anzureden, fertigte er (die Goldsachen).“ Alle Festgeräte dienen lediglich zum Kult gegen die Dämonen, d. h. um diese anzureden, und so auch die wenigen Goldsachen, die die Kágaba aus alter Zeit besitzen oder aus den Gräbern der Küste außerhalb ihres Wohngebietes gewinnen. Sie schmücken damit nur die Träger der Dämonenmasken und gebrauchen sie dazu öfters sinnwidrig. Hier ist also die Allmutter fälschlich an die Stelle der Gesamtheit der Dämonen gesetzt.

Als zwei Ausnahmen, in denen die Allmutter angerufen wird, müssen auch die folgenden beiden Gesänge gelten, zwei aus weit mehr als hundert von mir aufgeschriebenen:

„,Die Mutter der Feldfriichte, die Mutter der Flüsse wird uns Wohlwollen beweisen. Wem gehören wir? Aus wessen See (angeblich das Wasser im Leibe der Mutter) sind wir der Same? Der Mutter allein gehören wir an."

Deutlicher noch um eine dämonische Gabe wird in dem zweiten Gesang gebeten: bitten."

„Um Regen für die Feldfrüchte wird man am Wohnsitz der Mutter

Bemerkenswert ist hier das Wort bitten, das den Dämonen gegenüber nie angewandt wird. Soll das hier etwa ein Rest von früherem edlen Kult sein? Wohl sicherlich nicht, wie vorher überlegt ist, sondern eine naheliegende Überschreitung des Wesens der Allmutter.

Die Heilbringer, die bei den Kágaba mit den vier oder fünf Urahnen oder Urpriestern, den Söhnen der Allmutter, zusammenfallen, stellen diesen Typus ebenfalls sehr rein dar. Es sind Menschen mit übernatürlicher Kraft, die durch die Bezeichnungen alúna und Kalguǎšža aus-

1) Diese sind besonders Kultmittel zur Gewinnung der Hilfe des Sonnen. dämons. 
gedrückt wird. Der erstere Ausdruck wird auch von einigen anderen Vorfahren, von einigen Dämonen und von wenigen wunderbaren Erzeugnissen, aber auch vom Himmelsgewölbe (alunáura) gebraucht. Kalguašı̌za, das wohl von dem Wort für das männliche Glied (kalguákala) herzuleiten ist, wird außer als Bezeichnung für wenige andere Vorfahren als ein selbständiger Name der Allmutter angewandt, was im Zusammenhang mit der schon erwähnten Tendenz zu erklären ist, die Allmutter in eine männliche Gestalt umzuwandeln. Diese übernatürliche Kraft brauchten die Urahnen, um die Welt für den Gebrauch der Menschen herzurichten und die widerstrebenden Dämonen in ihren Dienst, d. $h$. in den Dienst der Menschen zu zwingen. Sie haben z. B. nach Utberwindung eines Feuerdämons die Ackererde geschaffen, sie haben Sonne, Mond und Morgenstern, die früher als Menschen auf Erden lebten und dort viel Schaden anrichteten, ihre Pfade am Himmel gewiesen, sie und ihre Nachkommen haben stagnierende Seen zum Abfluß gebracht, den Flüssen ihren Lauf gegeben $u$. dgl. m. Vor allem haben sie aber alle Einzelheiten des Kults eingeführt, indem sie die Naturdämonen überwanden oder überredeten, so daß diese mit ihnen Verträge abschlossen, denen zufolge sie sich auf besondere Art (durch Gesang, Tanz und Zaubersteinchen) ,anreden" lassen wollten. Auch nahmen sie den Dämonen die Gesichter ab, damit die Menschen in der Maske des Dämons tanzen und dadurch auf die Dämonen einwirken bzw. die Obliegenheiten des Dämons in der Natur selbst ausführen konnten. Kurz, die Urahnen leisten die Gewähr für die Wirkung der bestehenden Zeremonien. Da aber den Menschen die übernatürliche Kraft der Urahnen abgeht, die für die Ausführung der Dämonenkulte notwendig ist, so haben sie außer verschiedenen Maßnahmen zur Aufrechterhaltung der kultischen Reinheit, $d$. h. der übernatürlichen Kraft, die Einrichtung der Novizen getroffen. Diese jungen Tempellehrlinge erlangen durch jahrelange Abgeschlossenheit im Tempel, durch fortwährendes Singen und Tanzen, durch Fasten und Ausschluß von der Gegenwart der Frau - um nicht bloß geschlechtliche Enthaltsamkeit zu sagen - solche Zauberkraft, daß sie imstande sind, die Dämonenmasken wirksam zu tragen.

Dem Wesen der Heilbringer wird hier die Vollendung des Typus dadurch aufgedrückt, daß sie nach ihrem Tode in gar keiner Verbindung mit den Menschen stehen, obwohl sie nach ihrem Tode in den Bergen leben, die bei Lebzeiten ihre Tempel waren. Es besteht nur die Erinnerung an sie, aber kein Gesang, kein Tanz wendet sich an sie. Es gibt auch keinc Bildnisse und keine Masken von ihnen wie von den Dämonen. Der Untersehied zwischen ihnen und der Allmutter besteht aber darin, daß diese als dauernd lebendig und wirkend aufgefaßt wird, und daß die Taten der Urahnen nur am vorhandenen Material erfolgen, ebenso 
wie die Dämonenkulte nur von ihnen eingeführt werden, während die Allmutter die Dinge der Welt und die Zeremonien aus ihrem Wesen emaniert.

Naturgemä $B$ wenden sich die Heilbringer nur an die Dämonen, um mit ihnen Verträge über den ihnen zu widmenden Zauberkult abzuschließen, nicht aber an die Allmutter, und dementsprechend gibt es auch keine Maske von ihr, auch kein Bildnis wie von den Dämonen, denn alle Darstellungen von Dämonen oder Gottheiten haben zunächst eine zauberische Bedeutung diesen gegenüber, die an sich dem Wesen der Allmutter fernliegt. Trotzdem sind auch in dieser Beziehung vielleicht zwei UUberschreitungen ihres Typus festzustellen. So fertigt nach der Überlieferung die Allmutter einen Amtsstab für einen Vorfahren, als Zeichen seiner Priester- und Häuptlingswürde. Dieser Stab zeigt eine Figur, die vielleicht die Allmutter darstellen soll. Ferner wird berichtet, daß die Allmutter einst ein Bild von sich abnahm und es in Gold fertigte. Dieses schloß aber Priester Diuagatana, angeblich um Streitigkeiten über seinen Besitz zu vermeiden, in einen Berg ein. Beide Fälle sind also nur dazu angetan, darauf hinzuweisen, daß man auch mit dem Gedanken umgegangen ist, man müsse doch auch von der Allmutter ein Bild haben.

Die Dämonen, der dritte Bestandteil der religiösen Mächte, unterscheiden sich von der Allmutter und den Urahnen dadurch, daB sie von Hause aus als den Menschen widerstrebend und feindlich aufgefaßt werden, wodurch die Art des Kultus, der zauberische Zwang erklärlich wird. Es sind z. B. Dämonen der Sonne, des Feuers, des Donners, Regens, Schnees, der Seen, der Krankheiten und zahlreiche Tiere. Insofern ist das Beispiel der Kágaba besonders lehrreich und typisch. Trotzdem ist es keine Frage, daß auch bei den Kágaba im Laufe der Zeit aus einem bloßen Dämon, den man mit Anstrengung beeinflußt, allmählich ein Gott werden kann, dessen überwältigende und bei richtiger Anwendung segenbringende Macht nicht erzwungen, sondern vertrauensvoll erwartet und erbeten wird. Der größte Hinderungsgrund für eine solche Entwicklung ist aber die Allmutter und die Heilbringer. In ihnen liegt die Grundlage für das Vertrauen der Menschen in die Zauberkulte. So sehr sie also an sich die Zauberkulte durch ihre Existenz auf eine höhere Stufe heben, so müssen sie doch erst verschwinden oder sich mit den Dämọnen mischen, damit wirkliche Götter entstehen.

\section{Die Uitoto ${ }^{1}$.}

Wenn man von den Kágaba noch sagen konnte, sie hätten solche philosophischen Ideen von einer Allmutter und von Heilbringern, weil

1) Preuß, Religion und Mythologie der Uitoto. I, 1921, Göttingen. Vandenhoeck und Ruprecht. Bd. 2 ist in Druck. 
sie mit dem sog. Kulturvolk der Chibcha auf der Hochebene von Bogotá sprachverwandt sind, so ist eine ähnliche Annahme bei den Uitoto, Waldindianern und Bewohnern der Llanos zwischen Caraparaná und Igaraparaná und anderen nördlichen Zuflüssen des Isa oder Putumayó bis zum Yapurá oder Caqueta hin nicht mehr möglich. Denn diese sprechen eine isolierte Sprache und sind schwerlich von einem Kulturvolk des Hochlandes von Kolumbien oder Peru beeinflußt worden. Indessen muß man auch von den Kágaba, die heute ein elendes Völkchen sind und sicherlich nie eine höhere Kultur oder weit größere Volkszahl an ihren altangestammten Wohnsitzen in der Sierra Nevada de Santa Marta besessen haben, eher annehmen, daß sie eine gemeinsame Wurzel und nicht Entlehnungen mit den Chibcha verbinden. Von den Uitoto ist es für unsere Zwecke notwendig zu wissen, daß das Sammeln von Früchten und eine primitive Bodenwirtschaft auch für ihren Haushalt eine größere Rolle gespielt hat, als man früher von solchen Waldindianern und Tieflandbewohnern angenommen hat. Ferner ist zum Verständnis ihrer höchsten Gottheit zu bemerken, daß sie in kleinen exogamen Gruppen mit vaterrechtlichen Verhältnissen leben. Die Frau wird stets irgendeiner anderen Gruppe entnommen, deren es sehr viele, jede mit anderem Namen gibt, und siedelt stets zu der Gruppe des Mannes über. An der Spitze jeder Gruppe steht ein Häuptling mit beschränkten Befugnissen, der aber Leute hat, die sein Feld bearbeiten.

Die oberste Gottheit ist männlich, hat keine Frau und keine Kinder, wird aber kurzweg Vater (Moma) genannt, obwohl die Menschen nie seine Söhne heißen. Von ihm selbst wurde mir erzählt, daß er ohne Vater und Mutter entstand, in einer Textstelle heißt es, er entstand zuerst. Andere Stellen berichten aber darüber und über die Welt- und Menschenschöpfung Näheres. Aus ihnen geht hervor, daß er einem aus zwei Wesenheiten bestehenden Etwas, närnlich einem bloßen, fast existenzlosen Scheinding (naino) und der Erzählung, dem Fest (rafue) oder dem Wort (ikino) seinen Ursprung verdankt. Daher heißt er Nainuema, der das Scheinding ist, und Rafuema, der die Erzählung ist. Zugleich steht er, wie es bei Verkörperungen gewöhnlich ist, dem Scheinding und dem Wort als Besitzer gegenüber, schafft demnach die Welt aus dem Scheinding und gibt die Erzählung, das Wort, den Kult den Menschen. Trotzdem wird im einzelnen deutlich ausgedrückt, daß er geschaffeme Dinge aus seinem Leibe absondert, wie es sich bei einer Verkörperung gebührt.

Die Grenze des den Kulturarmen zuzumutenden philosophischen Denkens scheint dadurch überschritten zu sein, aber nicht nach der Seite des unbestimmten synthetischen Erfassens, sondern nach der Seite der klaren analytischen Sonderung und der Ausdrucksfähigkeit. Es ist 
schon hervorgehoben worden, daß die Idee der Verkörperung gerade den Kulturarmen ganz gewöhnlich und weit vertrauter ist als uns. Ebenso ist das Hervorgehen von Teildingen der Welt aus dem eigenen Körper demnach nicht weiter erstaunlich. Bei der Vorstellung, daß die Welt eine Frau ist wie die Allmutter der Kágaba, ergibt sich ohne weiteres daraus der Gedanke eines Gebärens, oder wie wir sagen, einer Emanation von. Dingen. Deshalb ist auch die Auffassung des Wortes, der Feste, des Kults als Bestandteil des verkörperten Dinges noch ohne Schwierigkeit zu begreifen, nachdem der Kult als etwas Uranfängliches, zum Bestehen der Welt Notwendiges erkannt war. Er muB demnach der Verkörperung der Welt ohne weiteres zuerkannt werden, und zwar als eine Substanz, wie z. B. auch der Schmerz bei den Hupa eine Substanz ist ${ }^{1}$ ). Geistiges und Körperliches wird eben nicht unterschieden, wie wir das so gern nach unsern vorgefaßten Meinungen über Animismus annehmen. Auch die Unterscheidung der Welt und des Wortes als Bestandteile der Welt ist nicht zu hoch für die Kulturarmen, da die Begriffe nicht aus dem Begriff Welt abgeleitet sind, sondern zu der gegebenen Vorstellung des bestehenden Weltalls die Instandhaltung und Ordnung durch den Kult hinzugetreten ist. Dagegen muß uns die klare Unterscheidung zwischen der Person des Weltschöpfers und der durch ihn verkörperten Welt insofern stutzig machen, als er selbst erst aus einem Scheinding und dem Wort entsteht. Es wird also nicht bloß die Welt und das Wort als zusammengehörig schlechthin angenommen, sondern eine scheinbar noch nicht personifizierte Vorstufe, das Scheinding, dem dann das Wort gleichfalls als eine Vorstufe an die Seite gesetzt wird. Das erlzlärt sich aus einer naturmythologischen Anschauung, die die Gestalt des höchsten Wesens, des Urvaters, von vornherein grundlegend beeinfluBt hat.

Das Interesse an der Welt liegt einmal an ihrem Bestehen als Grundlage des im Weehsel sich ernevenden Lebens und an dem Wechsel selbst, in dem die Erholtung alles Lebens zum Ausdruck kommt, und der durch den Kult beeinflußt wird. Der Wechsel erschien den Uitoto so wichtig, daß er ihnen das Wesen der Welt auszumachen schien. Dafür bot sich ihnen ein Symbol in dem sich ständig erneuenden Monde. Sie gelangten durch seine Beobachtung zu konkreten Vorstellungen über das Wesen der Welt und des sie verkörpernden Urvaters, die sie den auch sonst vorhandenen Auffassungen darüber hinzufügten. Auf diese Weise kamen sie dazu, die Welt aus einem Scheinding, dem dunkeln Monde, herzuleiten. Sie war nicht als Material bereits da und wurde nicht bloß der Form nach gestaltet, sondern man sagte sich, sie könne nur aus einem Scheinding entstanden sein, ähnlich wie die konkrete Mondsichel

1) Goddard, The Hupa, University of California Publications. Archaeology I Berkeley 1903/04, 5. 63. 
aus dem dunkeln Monde. Aus demselben Scheinding (naino) entstehen ihnen auch die neuen Früchte wie aus einem unerklärlichen Nichts. Die Welt bleibt zwar dauernd, aber ihr Wechsel in der Erneuung alles Lebens ist ein Wesensteil von ihr, und daher ist die Welt und natürlich auch der Urvater ein Abbild des Mondes. Auf diesem Wege wurde sein Geschick mit dem Werden und Vergehen des Mondes in Einklang gebracht.

Dadurch, daß ihm so ein Geschick überhaupt angedichtet wurde, trat etwas dem höchsten Gotte Fremdes in sein Wesen. Er wurde zur Verkörperung des Mondes, ohne dadurch aufzuhören, die Verkörperung der Welt zu sein. Seine Mondnatur drückt sich z. B. darin aus, daß er stirbt, daß seine Seele aber jedes Jahr in den Gewächsen und zur Zeit der Fruchtreife in den Früchten und in dem Kautschukball erscheint, mit dem zur Zeit der Fruchtreife als Symbol des Vollmondes gespielt wird. Sind die Früchte abgeerntet, so geht die Seele wieder an den Wohnsitz des Urvaters in der zweiten Unterwelt zurück. Seine Weltnatur ergibt sich daraus, daß er die Welt mit allem, was darauf ist, schafft bzw. emaniert, und daß er den Menschen den Kult, das Wort gibt, um die Folge der Mondphasen hervorzubringen. Obwohl er selbst in der Mondsichel am Fest der Jukareife erneut wird und direkt gesagt wird, daß seine Seele in den Früchten am Vollmondsfest und in einem zerbrechenden Baumstamm (dyadiko) als Symbol des vergehenden Mondes am sog. dyadiko-Fest erscheint, steht er doch als Weltganzes über den Festen. Denn er selbst hat sie ja angeordnet, weil er das ganze Weltgeschehen dadurch in Gang halten muß. Wir haben hier also den seltenen Fall, daß durch diese Verbindung von Weltgott und Monddämon eine einzige Gottheit entstanden ist, eine Art Monotheismus, neben dem es nur noch ganz bedeutungslose Dämonen gibt.

Um die Überordnung des höchsten Gottes über den bloßen Monddämon darzutun, braucht man nur auf die Weltschöpfung verweisen. Es ist eben nicht eine Schöpfung der Erde, sondern der ganzen Welt entsprechend der Natur der höchsten Gottheit als Verkörperung der Welt. Wir erkennen daraus auch deutlich die ursprüngliche Verbindung von Scheinding und Wort als fast existenzloser Substanzen.

„Ein Wahngebilde (naino), nichts anderes wàr vorhanden. Ein Truggebilde (naino) berührte der Vater, etwas Geheimnisvolles ergriff er. Nichts war vorhanden. Vermittelst eines Traumes hielt es Vater Nainuema (der das Trugbild ist) an sich und dachte nach. Kein Stab war vorhanden, um es zu halten: an einem Traumfaden hielt er den Trug (naino) mit dem Hauche. Er prüfte, wo der Grund des leeren Trugbildes (naino) sei, es war aber nichts da: ,Leeres knüpfe ich an. Nichts war dabei vorhanden. Jetzt suchte der Vater weiter, prüfte 
den Grund dieses Wortes (bikino) und tastete nach dem leeren Schein-, (naino)Sitz. Am Traumfaden knüpfte der Vater das Leere an und klebte den Zauberklebstoff arebaike (darauf) fest. Seinem Traume gemäß hielt er es mit dem Zaubermittel iseike. Den Trug(naino)-Grund nahm er in Besitz und stampfte ihn wiederholt. Darauf ließ er sich auf der ebenen, erträumten (Erde) nieder und trat sie eben. Den Trug (naino) hatte er im Besitz, da spuckte er wiederholt den Speichel aus dem Munde (damit der Wald wachse). Darauf ließ er sich auf diesen Teil (der Welt) nieder und nahm dieses Himmelsdach daraus. Im Besitze dieses Teils (der Welt) nahm er den blauen und den weißen Himmel davon fort, “

wie eine Haut, wie mir erläutert wurde. Dann wird geschildert, wie die Bäume wachsen, und wie er die Tiere einzeln schafft, ohne daß an dieser Stelle des Menschen Erwähnung getan wird.

Wie bei den Kágaba wendet man sich nicht an das höchste Wesen, um etwas von ihm zu erlangen, sondern gedenkt nur seiner. Ihm werden die Früchte und der Regen zugeschrieben, der die Früchte zum Gedeihen bringt. In beiden Fällen muß man dabei an seine Mondnatur denken, denn in den Früchten ist die Seele des Vaters, und als Mond verfügt er über das Wasser, das von dem Dunkelmond ausgeht. Sein Speichel ist, wie wir sehen, Wasser, durch das der Wald wächst. Deutlicher aber heißt es in der Überlieferung über das Fest der Jukareife, das zugleich das Fest der neuen Mondsichel ist:

„Bereits als der Vater die Worte (d. h. die Gesänge für das Fest) schuf, hatte er eine Trommel. Wenn er sie schlug, rief er sein Wasser an, und weil der Vater besondere Kräfte über das Wasser besaß, fiel es zum erstenmal rom Himmel herab. Als es herabfiel, regnete es vom Himmel auf die Erde, denn sonst kam es nicht vom Himmel herunter. ${ }^{t}$

Die Sehlitztrommel ist ein Symbol für den Dunkelmond, aus dem das Wasser, die Flut kommt. Aber die beiden Naturen, die Welt- und Mondnatur, sind nicht gut voneinander zu trennen, und jedenfalls ist die Art des Gedenkens dem höchsten Wesen angemessen.

Nur in zwei Gesängen kommt derartiges vor. Es heißt z. B. in einem Gesang des Festes der Fruchtreife:

„Wieder haben wir eine Menge Früchte von den Gewächsen gepflückt und erzählen hier Geschichten ${ }^{1}$ ). Gut sind die Friichte des Vaters geraten, ob er uns auch vortäuschte, daß sich keine (im Winde)

1) An diesem Fest werden Erzählungen über die Entstehung jeder einzelnen Fruchtgattung aus dem Zustand des Scheindinges (naino) in dem erwähnten Sinne erzählt. Es handelt sich dabei wahrscheinlich um entsprechende Mond. mythen. 
schaukeln würden ${ }^{1}$ ). Gut ist die Chicha (aus Früchten der Canaguchepalme) ausgefallen, obwohl (noch eben) keine da war..."

Ein anderer Gesang desselben Festes lautet:

„Nun erzählet Geschichten ${ }^{2}$ ). Denn es blühten die Blumen, indem der Vater, Dyonera Buneima (d. h. der Buneima der Erzählung) in der Unterwelt gutes Wasser (auf die Erde) warf. Dyonera, wem sonst, entsprang das Wasser, daß die Blumen schön blühten. Es täuschte uns der Vater, daß keine (Früchte) sich (im Winde) wiegen würden, als er (nach der vorigen Ernte) in die Unterwelt entwich" 3).

Bei den Uitoto treffen wir nun auch die Erscheinung an, daß die höchste Gottheit den Tod sendet, gegen den es dann kein Mittel gibt, und der ohne Versuch der Umstimmung hingenommen wird. Das wird ähnlich wiederholt z. B. von Afrika berichtet und ist von Söderblom als zu ihrem Wesen gehörig hervorgehoben worden. Scheinbar liegt der Fall aber bei den Uitoto ganz anders, denn hier sterben die Menschen, weil der Urvater selbst stirbt und dann nur als Seele wirkt, $d . h$. hier: sich immer wieder erneut. Dieser Unterschied erscheint mir aber nicht in dem Maße vorhanden, denn in beiden Fällen wird der Tod als zur Ordnung der Welt gehörig aufgefaßt und daher in dem höchsten Wesen, der Verkörperung der Welt, verankert. Wie sich der Gott durch die Abgabe des Kults an die Menschen der persönlichen Einwirkung auf die Welt begeben hat, so sind überhaupt die Grundzüge des Weltbestehens und der Welterhaltung, d. h. des Wechsels in der Erneuung des Lebens festgelegt, und dazu gehört auch der Tod. Man darf daher nicht sagen, wie es vielfach geschehen ist, daß die Kulturarmen den Satz ,,alle Menschen müssen

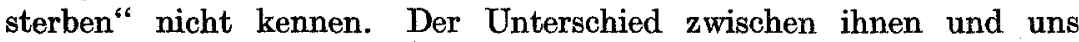
besteht nur darin, daß wir analytisch zu dieser Zusammenfassung kommen, während ihnen die Einsicht als in dem Wesen der Welt, d. h. der höchsten Gottheit begründet erscheint. So ist vieles den Kulturarmen Offenbarung, d. h. plötzliche Eingebung und Glaube, was uns Erkenntnis und Wissen ist. Richtiger als ihr Glaube ist aber unsere Erkenntnis vielfach nicht, im Gegenteil besteht das Wesen des sog. Kulturfortschritts in geistiger Beziehung meist nur darin, da $\beta$ wir uns trotz unseres zergliedernden Denkens auf derselben Höhe halten wie frühere Zeiten und nicht dadurch auf naturwidrige Abwege gelangen. So ist auch das höchste Wesen den Kulturarmen von vorneherein nicht eine willkürlich herrschende Persönlichkeit, sondern sie ist als Ganzes ebenso gebunden, wie ihr Symbol, der Mond, bei den Uitoto durch den wird.

1) Wie der dunkele Mond vortäuscht, daß kein Vollmond daraus entstehen

2) Vgl. S. 177 Anm. 1.

3) Es ist damit seine Seele gemeint, die in den Früchten sitzt. 
immerwährenden Kreislauf der Phasen in seinem freien Willen aufs höchste beschränkt ist. Nur leuchtet uns die Gebundenheit der Gottheit durch die Mondphasen viel mehr ein. Vorhanden aber ist der Kreislauf des Wechsels auch ohne Identifizierung der Welt und des höchsten Wesens mit dem Mond. Daher müssen wir auch die unfreiwillige Einführung des Todes für die Menschen durch den Tod des Urvaters ebenso auffassen wie die Sendung des Todes durch das höchste Wesen bei anderen Völkern.

In der Schilderung des Festes der Fruchtreife ist die Einführung des Todes naturmythologisch näher begründet.

„So gelangten wir von einem Orte (unter der Erde) nach einer Stelle oben auf der Erde, indem unsere Vorfahren aus einer Höhle kamen. Dort oben ruhten wir uns aus. Dann ging Husiniamui (einer der Vorfahren) aus unserer Mitte dort nach oben an den Himmel und nahm die Erzählungen (rafue) und das Feuer mit. $\mathrm{Da}$ das Feuer gut war, starb er nicht. Weil aber das Feuer, das er uns gab, nicht gut war, starben wir. Infolgedessen stirbt Husiniamui nicht, während wir, nachdem wir (einmal) gestorben sind, das Wort (ikino) kennen, daß wir sterben. So starb der Vater (das höchste Wesen), obwohl das Wort (davon noch) nicht bestand ..."

Durch diese Darstellung wird ohne weiteres zugestanden, daB die Einrichtung des Todes eine Unvollkommenheit einschließt, und daß der Urvater gegenüber dem Häuptling Husiniamui, der nebst den anderen Vorfahren aus einer Höhle am Ort des Sonnenaufgangs auf die Erde gelangte, zurückstehen muß, da dieser das gute Feuer mitnahm. Aber trotz alledem bleibt Husiniamui, der der Sonnendämon ist, für die Religion der Uitoto untergeordnet, obwohl der Text an dieser einzigen Stelle angibt, daß er außer dem guten Feuer auch dic Erzählungen, d. h. die Ordnung für alles Geschehen, mitnahm. Diese Verkörperung alles Geschehens in der Welt verblieb dem Urvater, obwohl er nur als Mond das schlechte Feuer besaß und deshalb sterben mußte. Wir können aber dieser Stelle entnehmen, daß der Uitoto einst vor der Entscheidung gestanden hat, ob er nicht das höchste Wesen mit der Sonne identifizieren solle, wie wir es -in größerem Maße bei den Cora finden werden. Für die Ordnung in der Welt war ihm aber das Mondsymbol einleuchtender, und wir werden sehen, wie sich die Cora verhalten müssen, damit ihr Sonnenwesen die Obliegènheiten der höchsten Gottheit, den Wechsel in der Welt zu ordnen, erfüllen kann.

Gerade bei den Uitoto tritt es besonders hervor, daß der Besitz des Wortes, der Erzählungen dem höchsten Wesen, das sein Symbol im Monde fand, zukommt. Aus dem Wort entsteht der Urvater. Es steht 
noch über ihm, es ist die Urordnung, das eigentlich Wirkungsmächtige in der Welt. "Wir kennen das Wort, daB wir sterben" bedeutet, wir wissen, daß es eine solche Urordnung gibt. „So starb der Vater, obwohl das Wort (davon noch) nicht bestand, " bedeutet: der Urvater war zwar aus dem Wort, dem Dunkelmond, entstanden, daß er aber nach Erreichung seiner vollen Größe als Vollmond sterben sollte, das war beim erstenmal noch nicht offenbar geworden und von ihm nicht vermutet worden.

Die Textstelle über den Ursprung des Vaters aus dem Wort und seine schöpferische Tätigkeit findet sich in der Uberlieferung über das dyadikoFest, das das Vergehen des Mondes durch Zerbrechen eines ihn darstellenden Baumstammes zum Zweck der Erneuung der Welt im Wechsel herbeiführen soll.

„Im Anfang gab das Wort dem Vater den Ursprung. Nachdem dieser als das Wort das Wasser geschaffen hatte, machte er darin die Pflanze nuisi. Nachdem er sie im Wasser von sich abgesondert hatte, setzte er eine Schlange (nuio) auf den Grund unter die Oberfläche des Wassers, die darin sitzen blieb. Als er die Schlange, die er machte, (von seinem Leibe) abgesondert hatte, sah er, dab wir die ersten (Menschen) sein würden, und es entstand der IIäuptling. Dieser sah einen Baum foidoroina, der als Seele des Vaters dastand, den dyadireBaum, der als Seele der Schlange im Walde dastand, und machte daraus den dyadiko..."

Dieses ist eigentlich auch die Erzählung von der Entstehung der Welt, was aus der plötzlich erwähnten Menschenschöpfung hervorgeht. Aber sie ist vollständig in den Ideen stecken geblieben, die man den Wandlungen des Mondes entnahm. Das Wort wird Person, d.h. aus dem Dunkelmond wird der Weltschöpfer. Als Verkörperung der Wortes, d. h. des Dunkelmondes schafft dieser das Wasser. Er ist nämlich von vorneherein selbst das Wasser, weil der Dunkelmond als Wasser aufgefaßt wird und von diesem das Wasser ausgeht. Er sondert darauf im Wasser von seinem Körper das Gewächs nuisi und die Schlange nuio ab. Das will besagen: Aus der Substanz des Wassers bildet sich der Keim, aus dem später die Mondsichel wird. Die Uitoto haben nämlich einen Mythus von einer winzigen Schlange nuio, die von Wasser zunächst nicht zu unterscheiden ist. Diese ist der Keim der Mondsichel, in den sich der ,gelähmte Buneima", der vergehende Mond, verwandelt hat. Die Schlange wird nach und nach sichtbar und vermöge ihrer Gefräßigkeit allmählich sehr groß. Schließlich verschlingt sie mit dem ihr dargereichten Futter zugleich das Mädchen, das es ihr hinhält. Deren Vater springt in ihren Rachen und schneidet ihr, während sie weiter Mengen von Menschen verschlingt (Vollmond, Sternverschlingen), im Laufe eines langen Zeitraumes nach und nach den Leib auf 
(abnehmender Mond) und springt endlich aus der Leibesöffnung heraus (Mondsichel), während die Schlange verendet (Dunkelmond). Das Gewächs nuisi wiederum ist noch eine Vorstufe von der Schlange nuio, ebenso wie es in einem andern Mythus einen Baum améosi gibt (Dunkelmond), dessen Seele der Blitz (amēo), die hervorkommende und wachsende Mondsichel, ist.

Der Urvater in unserer Textstelle sieht nun weiter, daß wir die ersten Menschen sein würden: Die Entstehung oder Geburt der Menschen bereitet sich vor. Der Häuptling entsteht, d. h. er löst sich von dem Urvater (als Dunkelmond) als die neue Mondsichel ab. Der Häuptling ist an Stelle der Schlange ein anderes Bild für die Mondsichel und steht verglichen mit der andern Erzählung von der Weltschöpfung, wo die Welt aus dem Scheinding naino (dem Dunkelmond) hervorgeht, an Stelle der Welt. Nach anderer Auffassung kommen die Häuptlinge, die ersten Menschen, aus einer Höhle in der Erde im Sonnenaufgang. Das ist aber nur dasselbe Bild der Entstehung der Mondsichel aus dem Dunkelmond, indem die ganze Welt (Erdinneres) an die Stelle des Dunkelmondes getreten ist. Die Menschen sind in allem Mondwesen und nehmen an dem Schicksal des Mondes teil, wie auch aus ihrem Tod hervorgeht.

Der Text versetzt uns nun in die menschlichen Verhältnisse. Wie eir Baum als Symbol des vergehenden Mondes für das dyadiko-Fest ausgewählt, dünn gehauen und durch Tanz auf ihm zerbrochen wird, so sieht der entstandene Häuptling einen Baum als die Seele des Vaters und zugleich als die Seele der Schlange, die beide als Symbol des sichtbaren Mondes identisch sind, und wählt ihn für das Fest zum Zerbrechen aus.

So ist der Urvater in allen Einzelheiten mit dem Bilde des Mondes verwachsen, auch wo er als höchster Gott, $d$. h. als Welt- und Menschenschöpfer und als Inhaber des Wortes erscheint. In erster Linie tritt auch das Wort wie bei andern Völkern nicht als ursprüngliche Weltordnung, sondern als Zauiberkult hervor, den die Gottheit den Menschen zur Aufrechterhaltung der Weltordnung gibt. Immer wieder wird hervorgehoben, daß das Wort, die Erzählung vom Urvater den Menschen gegeben ist, und daß die Vorfahren, als sie aus der Höhle kamen, sie auf die Erde brachten. Insofern sind die ersten Häuptlinge die Heilbringer. Als der Urvater die Welt aus dem Scheinding (naino) geschaffen hatte, „machte Rafuema (= der die Erzählung ist oder hat) am Fuße des Himmels (d. h. in der Unterwelt) nach langem Nachdenken diese Erzählung davon, damit wir sie oben auf die Erde bringen", heißt es in dem Schöpfungsbericht. Darin ist ausgedrückt, daß selbst diese Erzählung durch den bloßen Vortrag einen Einfluß auf das Bestehen der Welt ausübt. Deshalb wird sie, ebenso wie es mit den andern Mythen geschieht, an bestimmten Festen mitgeteilt. 
Der Gebrauch des Wortes zur Bezeichnung des Kults tritt z. B. in der Uberlieferung über das Fest der Jukareife hervor.

„Als im Anfang noch niemand vorhanden war, schuf der Vater das Wort und gab uns dieses Wort vom Jukabaum. Nofuyeni, und unsere (andern) Vorfahren brachten dies Wort auf die Erde. Nachdem er es vermittelst eines Traumes hinaufgebracht hatte und hinter ihm her unsere Vorfahren (gekommen waren), verwirklichten sie das Wort und gaben es uns auf der Erde. Mit diesem Worte tanzte Okinuyēma (ein Vorfahr) die ganze Zeit über ohne Aufhören. Unaufhörlich sang und sprach und tanzte er dasselbe Wort. Aber obwohl er es uns hier auf Erden lehrte, kehrte er nicht auf die Erde zurück. Er lehrte es uns nur, solange er hier oben war. Nun befinden er und sie (die Vorfahren) sich dort unmittelbar unter uns. Dort halten sie sich in ihren Hütten auf und sprechen das gute Wort. Seitdem sie dort unten weilen, sind sie nicht gestorben und befinden sich dort unten sehr wohl. Und einst gehen wir dorthin. Infolgedessen sprechen und singen wir zuweilen das Wort, das auch das Wort des Vaters Buneima ist, zu Okinuyema. Indem wir mit dem Wort das Fest okima (das Fest der Juka) veranstalten, unterhalten wir uns über das Wort im Beginn der Tänze..."

Die ersten Vorfahren sind also die Uberbringer des Wortes, das sie durch einen Traum vom Urvater erhalten haben, und lehren es die Menschen bei ihren Lebzeiten. Sie sind die natürlichen Heilbringer wie die Vorfahren der Kágaba, doch hat die Tätigkeit der letzteren auf Erden mehr Selbständigkeit, obwohl auch sie, soweit der Kult in Betracht kommt, letzten Endes auf die Allmutter zurückgeht. Die Vorfahren der Uitoto stehen aber im Gegensatz zu denen der Kágaba auch nach dem Tode mit den Uberlebenden in Verbindung, indem sie in der Unterwelt die gleichen Feste feiern wie ihre Nachkommen über ihnen und dadurch die Aufrechterhaltung der Ordnung in der Welt unterstützen. Tatsächlich tritt die gegenseitige Verbindung der Bewohner der beiden Welten an den Festen stark in die Erscheinung. Das Wort, von dem hier geredet wird, ist einmal die Erzählung vom Jukabaum, der alle Früchte der Erde trägt, ein Mondmythus, den sie an den Abenden vor dem eigentlichen Fest erzählen, augenscheinlich, damit sie eine ähnliche Fülle erzielen, und ferner die Summe der Tänze, Gesänge und mimischen Darstellungen, die sich auf das Hervorbringen der neuen Mondsichel beziehen. In der Tat wird dieses Fest, an dem ich teilgenommen habe, gefeiert, wenn die neue Mondsichel sichtbar wird.

Daß der Sinn der „Erzählung“ (rafue) die genannten beiden Bedeutungen als bloße, trotzdem aber zauberisch wirkende Uberlieferung und als Inbegriff der Kulthandlungen hat, ersehen wir auch aus dem Text über das Fest der Fruchtreife (Vollmondsfest). 
„... Als der Vater gestorben zu sein schien, hörten wir die Erzählung (rafue), die der Vater uns gab, und freuten uns ihrer, als wir sie (auf die Erde) brachten. Aus diesem Grunde tanzen wir, um uns damit der Seele des Vaters in dem Kautschukball zu erfreuen, und wir freuen uns damit (zugleich) der Äußerungen (uaina) des Kindes (d. h. des Balles). Daher vergessen wir nicht das gute Wort (marekkino) in dem Ball, geben dem Kind Vacurifrüchte zu essen und bringen ihm Cumarefrüchte und alle möglichen andern zu essen, um es nach dem ,Scheinding" (naino) (d. h. nach ihrer Entstehung aus dem Scheinding) zu fragen. Daher fragt jeder, der welche bringt, nach dem Scheinding ..."

Die neuerschienenen Früchte und der neuerschienene Kautschukball sind Symbole des neugewordenen Vollmondes und werden deshalb, wie auch vielfach die verschiedenen Symbole der Mondsichel am Fest der Jukareife, das Kind genannt. Die Gesänge des letzteren Festes schildern, wie sich die Vorfahren in der Unterwelt, d. h. im Dunkelmond erneuen, und wie das Kind bei ihnen erscheint, aus ihnen herauskommt. Derselbe Gedanke wird noch deutlicher im Fest der Fruchtreife ausgedrückt. Aus der zweiten Unterwelt, dem Dunkelmond und Sitz des Urvaters, erscheint seine Seele, das Kind und befindet sich nun in den Früchten und in dem Kautschukball. In ihnen ist aber auch das "gute Wort", das sie hervorgebracht hat, die Substanz der Weltordnung und des Kults. Dieses Wort ist die andere Seite des "Scheindings" (naino), aus dem die Welt und die Früchte entstanden sind, und deshalb ist der Hauptinhalt des Festes außer dem Spiel mit dem Kautschukball, daß in endloser Folge immer zwei Leute mit je einer Gattung der Früchte ankommen und tanzend den Herrn des Festes nach der Entstehung aus dem Scheinding fragen, woraut ihnen dieser angeblich mit einer Erzäblung dient. Nach dem Text zu urteilen, fragen sie aber das Kind selbst und freuen sich seiner Äußerungen. Sie füttern nach dem Wortlaut auch das Kind, den Ball, mit den Früchten. Das soll heißen, sie bringen ihm das mit ihm Identische als sein Eigentum. In Wirklichkeit essen die Leute die Früchte auf, aber es scheint, daß ihnen erst von dem Fest ab der unbeschränkte Genuß der Früchte erlaubt ist, wie das für das Fest der Jukareife nachgewiesen werden kann.

$\mathrm{Da} B$ hier wie auch in der Utberlieferung über das Fest der Jukareife von dem guten Wort gesprochen wird, liegt an dem zum Wechsel des Weltgeschehens notwendigen Vorhandensein des schlechten Worts. Das gute Wort bedeutet den einen Pol der Welt, die Fruchtreife, das sohlechte die Abwesenheit der Früchte, d. h. den Tod. Beides wird durch die Phasen des Mondes, den leuchtenden und den dunkeln Mond, symbolisiert. Man tut gut, sich zu vergegenwärtigen, wie die Mythen dieses Stammes, die alle auf den Mond Bezug nehmen, von Gegensätzen 
der Art voll sind; um zu verstehen, daß auch diese Mythen, die an den Festen vorgetragen werden, als Wort auf das Weltgeschehen einwirken sollen. Auch begreift man daraus, daß die Person des höchsten Gottes, des Urvaters, als Erhalter der Welt mit dem Monde als Gesamtheit zusammenfallen konnte. Ich setze daher die wesentlichsten Gegensätze der Art, ohne mich auf Symbole im einzelnen dabei einzulassen, hierher.

\begin{tabular}{l|l}
\multicolumn{1}{c|}{$\begin{array}{c}\text { Dunkeler Mond } \\
\text { Dunkelheit, schwarze Farbe, Asche }\end{array}$} & $\begin{array}{l}\text { Heller Mond } \\
\text { Helligkeit, weiße, rote, gelbe Farbe, } \\
\text { Feuer, Blitz } \\
\text { Herauskommen }\end{array}$ \\
$\begin{array}{l}\text { Verschlossensein } \\
\text { Häßlichkeit, Runzeln, Flecken } \\
\text { Unfruchtbarkeit, Verwelken, Mangel }\end{array}$ & $\begin{array}{l}\text { Schönheit, Glätte, Glanz } \\
\text { Fruchtbarkeit, Fruchtfülle, Ge- } \\
\text { deihen, Reichtum }\end{array}$ \\
Krankheit, Augenkrankheit & $\begin{array}{l}\text { Genesung, Gesundheit } \\
\text { Sterben, Tod, Augenverlust, Schädel }\end{array}$ \\
Flut, Regen, Tränen, Krankheit & $\begin{array}{l}\text { Neuerstehen, Leben, Gesicht } \\
\text { Schönes Wetter, Heiterkeit, Ge- } \\
\text { sundheit. }\end{array}$
\end{tabular}

Diese Gegensätze sind so sehr rein menschlich und haben so wenig mit dem Monde zu tun, daß die Frage entsteht, ob nicht der bloße psychische Trieb, solche Gegensätze herauszuarbeiten, zur Entstehung von Geschichten führt und erst später die Einführung der zahlreichen besonderen Mondsymbole und die Darstellung wirklicher, der Veränderung des Mondes entnommener Mondschicksale hinzutritt. Die Beantwortung ergibt sich vielleicht aus folgendem. Menschliche Schicksale spiegeln natürlich stets Tod und Leben, Krankheit und Gesundheit, Fülle und Mangel, Nacht und Tag usw. wieder, eine Gegenüberstellung von Symbolen dafür findet sich in einiger Fülle und besonderer $\mathrm{Zu}$ spitzung aber nur bei Mondmythen und sonstigen Gestirnmythen. Die Befruchtung einer vorhandenen psychischen Neigung zu entsprechenden symbolischen Gegensätzen durch den Mond erscheint gegeben, aber das Ergebnis als Mythus ist der von vornherein bei der Bildung von Erzählungen erfolgte Zusammenschluß von beiden.

Für die uns beschäftigende Frage nach dem Zusammentritt der höchsten Gottheit mit dem Monde ist dieses Ergebnis aber auch von Bedeutung. Die Verkörperung der Welt in ihren beiden Bestandteilen des Bestehens und der Ordnung im Wechsel hat an sich mit dem Monde nichts zu tun. Daß Mond und höchstes Weser hier zusammenfallen, kann daher später eingetreten sein, braught es aber nicht zu sein. Heute haben wir sie als untrennbare Einheit.

Die Dämonen werden bei den Uitoto durch einige Krankheit verursachende Seelen von Vorfahren vertreten. Zum Teil sind diese Seelen Krankheitsstoffe, die von der Substanz des dunklen Mondes, dem Inbe- 
griff von Krankheit und Tod, ausgehen. Dazu gehört z. B. der zauberisch wirkende Regentropfen. Da die Seelen des Stammes in der Signaltrommel sitzen, die ein Symbol des Dunkelmondes ist, so ist sehr natürlich, daß auch die Seelen der Vorfahren in engster Verbindung mit dem Dunkelmond stehen. Denn sie erneuen sich selbst in der neu hervorkommenden Mondsichel, wie das von den Vorfahren in der Unterwelt in den Gesängen des Festes der Jukareife erzählt wird, das die neue Mondsichel zum Inhalt hat. Die Menschen sind eben Mondleute, und der Aufenthalt der Vorfahren in der Unterwelt ist eigentlich ein Verweilen im Dunkelmond. So hat auch hier die Mondidee vielleicht frühere Vorstellungen von den Toten vollkommen in sich aufgenommen. Um die schädlichen Seelen zu vernichten, wird das Fest des Ergreifens der Seelen gefeiert. Auch dieses müßte man auf den Urvater zurückführen. Leider fehlt aber eine direkte Uberlieferung darüber.

Wenn man den einzigen Dämon in Betracht zieht, der noch eine gewisse Bedeutung hat, den schon genannten Sonnendämon Husiniamui, so ist vorher zu betonen, da $\beta$ auch er nach der Uberlieferung ein aus der Höhle, dem Dunkelmonde herauskommender Mensch war wie alle übrigen Menschen und erst später seine selbständige, dem Urvater gegensätzliche Stellung einnahm. Der Urvater verkörperte also auch trotz seiner nach der ursprünglichen Idee die gesamte Welt. Andererseits ist aber bereits darauf hingewiesen, daß er durch die Mitnahme der Erzählungen an den Himmel einen Anlauf machte, selbst ein höchster Gott zu sein, da sie seinem Wesen, dem guten, unsterblichen Sonnenfeuer entsprachen, das er gleichfalls an den Himmel nahm. In dem Mythus von der Entstehung des Jukabaumes gibt es noch eine andere Anspielung auf seine Natur als höchster Gott. Es wird nämlich gesagt, daß ihn die andern Häuptlinge unter dem Namen Kuyo verbrannten, weil sie den Namen Husiniamui gern hatten, d. h. weil sie ihn als Sonne am Himmel sehen wollten, und diesen Namen nahm er an den Himmel mit. „Es verbrannte Kuyo, es verbrannte sein Wald," heißt es nun im Text, als ob er ein Schöpfer der Vegetation sei, und zugleich wurde die ganze Erde umgestürzt, als ob sie seine Erde sei. Obwohl diese Andeutungen nirgends eine Bestätigung durch andere Tatsachen erhalten und Husiniamui ein bedeutungsloser Sonnendämon bleibt, so werden wir sie doch für das Verständnis des höchsten Wesens bei den Cora nötig haben.

Der Sonnendämon ist nur das Vorbild des Kampfes und der Menschenfresserei, indem er die Mondwesen köpft und sie zusammen mit seinen Leuten verzehrt. Daher heißt er Husiniamui, d. h. der Kampfeswütige. Den menschenfressenden Uitoto gegenüber ist er aber nicht ein Schützer im Kampfe und beim Menschenfraß, sondern der Dämon ist im wesentlichen mythisch. Aber nach dem Fraße hat man sich in einem Feste 
gegen die tierischen. Wesen zu verteidigen, die vom Ort des Sonnenaufgangs her den Tod und das Auffressen rächen wollen, vor allem gegen die Seele des Gefressenen, dessen Gefolgschaft die übrigen feindlichen Dämonen zu sein scheinen. Man tanzt daher mit einer Holzpuppe der Seele des Gefressenen und mit Nachbildungen der betreffenden tierischen Dämonen, stellt auch an einigen besonders gefährlichen die Vernichtung im Abbilde dar. So ist der Sonnendämon selbst als feindlich aufzufassen. Auch in diesem Falle ist das Fest wegen mangelnder Ubberlieferung nicht ohne weiteres auf das „Wort“ des Urvaters zurückzuführen, wie es am wahrscheinlichsten ist.

\section{Die Cora ${ }^{\mathbf{1}}$.}

Die Cora in der Sierra del Nayarit, dem südlichen Teil der Sierra Madre Occidental in Mexico, sind mit den alten Mexikanern ebenso sprachverwandt wie die Kágaba mit den Chibcha, aber auch für sie gilt der Satz, daß ihre Religion nicht von der des alten Kulturvolks entlehnt, sondern beider Religion einer gemeinsamen Wurzel entsprossen ist. Sie leben vom Ackerbau, und ihre soziale Grundlage ist die vaterrechtliche Familie, die bei ihren Feldern wohnt, aber alle Siedelungen gehören zu Dörfern, an dessen Spitze je ein gewählter Häuptling mit sehr beschränkter Macht steht.

Da wir die altmexikanische Religion zum Vergleich zur Verfügung haben, die große Ähnlichkeiten mit der der Cora aufweist, so erhalten wir für das Verständnis der Stellung der höchsten Gottheit eine bedeutende Stütze, die um so notwendiger ist, als auch hier wie bei den Uitoto der oberste Gott mit einem einzelnen Naturobjekt verbunden ist und auch der Heilbringer zugleich ein Naturdämon ist. Die Sonderung der einzelnen Bestandteile wird noch dadurch erschwert, daß die höchste Gottheit eine Parallelgestalt hat, die mit einem andern Naturding verbunden ist.

Im Altmexikanischen ist die höchste Gottheit eine Art Ehepaar, erscheint aber in ihrem Wirken als Einheit und ist durch ihr fast vollständiges Fernbleiben von einzelnen Naturobjekten und dadurch, da $B$ jeder Kult ihnen gegenüber fehlt, ohne ,weiteres als solche gekennzeichnet. Wir können daher nicht sagen, daß ein männliches und ein weibliches Prinzip gleich dem Sonnengott und der Erdgöttin, die die Mexikaner außerdem hatten, in der obersten Gottheit etwas Notwendiges und eine Art Parallele zu Himmel und Erde sei, die sich zum Gedeihen des Wachstums begatten, sondern die Zweiheit im höchsten Wesen entspricht nur der sozialen Stellung von Mann und Frau. Wir dürfen daher auch bei den Cora als höchstes Wesen kein Paar suchen, in dem jeder Teil unabhängig vom andern selbständig wirkt, eben den

1) Preuß, Die Nayaritexpedition I. Leipzig 1912. 
Sonnengott und die Erd- und Mondgöttin, die beide manches von dem Wesen der höchsten Gottheit an sich haben, sondern dürfen nur einen von ihnen als ursprüngliches höchstes Wesen annehmen.

Der Sonnengott hat nur den Namen „unser Vater" (Tayáu), hat keinen bestimmten Wohnsitz, obwohl ihm das Attribut ,im Himmel" zukommt. Es wird vielmehr in den Gesängen beschrieben, wie er jenseits seiner Erde herabsteigt oder im „Lebenswasser" im Westen verschwindet, wie er wieder auf seine andere Welt herauskommt und mittags auf einem gelben Stuhl ausruht. Beim Untergehen wird ihm die Ausbreitung der Nacht zugeschrieben, indem er Rauch aufwirft, nachtschwarze und dunkelrote Wolken ausbreitet und den Abend und die Nacht, ,aufwirft". Diese Tätigkeit geht also bereits über den natürlichen Bereich des lichtspendenden Tagesgestirns hinaus, und das ursprüngliche allumfassende Wesen des Gottes scheint dadurch klar zu werden, daß auch der Adler, der Feuer und Licht schlechthin verkörpert, einmal "unser Vater" genannt und mit dem Sonnengott nach Aussage der Cora in gewisser Weise identifiziert wird. In der Mitte des Festplatzes, der die Welt darstellt, wird am Beginn des Festes am Abend das Feuer entzündet, das die Federn ,,unseres Vaters " genannt und durch einen daneben gesteckten Stab mit den rötlich, blau und gelb schillernden: Federn des Arara symbolisiert wird. Es wird nach einem Gesange bei Sonnenuntergang vom westlichen Rande der Welt geholt. Sobald die Flamme entsteht, erscheint der Adler noch nackt und ohne Federn und hält (als flackerndes Feuer) mit den ringsum sitzenden "Alten", den Leitern des Festes, unermüdlich Zwiesprache. Gegen Morgen wachsen ihm die Flügel, und er fliegt zum Himmel empor, wo er die nächtliche Schlange, die vom Morgenstern durch einen Pfeilschuß erlegt wird, verzehrt. Man sieht aus allen Angaben, daß ein Unterschied zwischen Sonne und Tageslicht gemacht wird, als ob das letztere nicht von der physischen Sonne ausgeht. Deutlich wird das in der Beschreibung der Mitte des Festplatzes als ,das Feuer, das die Sonne darstellt, der Mittelpunkt der Welt, wo unser Vater, die Sonne, wohnt". Die Sonne geht ja, wie in den Gesängen geschildert wird, unter und kommt erst bei Sonnenaufgang wieder auf ihre ,andere Welt". Die Erklärung dieses Widerspruchs liegt demnach in der späteren Verkörperung des Feuerwesens in der Sonne, die aber noch nicht durchgeführt ist.

Hier findet sich auch bereits ein Widerspruch gegen diese Auffassung, weil nämlich die Erd- und Mondgöttin, ,unsere Mutter“, in einem Mythus zu dem Adler, nachdem er von dem Festplatze zum Himmel emporgeflogen ist, spricht: „Dort bleibe und ergreife die Welt. Ihm gab sie die Wolken; mit ihnen ergriff er die Welt. Mit ihnen hält er seine Welt" (S. 194). Danach hat also die Erdgöttin und nicht die Sonne die 
Herrsehaft über den Lichthimmel, und das Feuer des Adlers scheint von ihr auszugehen.

Die höchste Gottheit, als die wir Tayáu ansprechen könnten, war also vielleicht, wie die Allmutter der Kágaba, besonders die Verkörperung des Feuers als des wesentlichsten Teils der Welt, die der höchste Gott verkörpern soll. Bei der Allmutter der Kágaba war nun folgerichtig von diesen festgehalten, daß die einzelnen Gestirne, z. B. die Sonne, ebensc wie alle andern Naturobjekte Dämonen seien, die in ihren Bezirken wirken, und die die Menschen vermöge des von der Allmutter gegebenen Kults in Ordnung halten. Da aber bei den Cora die höchste Gottheit selbst zur Sonne geworden war, so traten die Hauptgestirne Mond, „unsere Mutter" [Taté $\left.\left.x^{1}\right)\right]$, und Morgenstern, „unser älterer Bruder", zu ihm in ein nebengeordnetes Verhältnis als Frau und Sohn, die ihm wie im sozialen Leben untergeben sind. Wir finden die drei Personen daher schon im Himmel vor, bevor die übrigen Naturdinge, darunter die Erde, geschaffen werden. Die Schöpfung dieser Dinge muß dem Wesen der Mondgöttin, die zugleich Erdgöttin und der Mais ist, anscheinend naturgemäß eher zukommen als dem Sonnengott, da sie die Verkörperung der Erde ist. Deshalb setzt sie nur dem Sonnengott und dem Morgenstern ihren Plan suseinander und fragt sie, ob er ihnen gefalle.

Der Anfang des Gesanges von der Dầmonen- und Erdschöpfung lautet entsprechend:

„Es dachte nach unsere Mutter, was geschehen wird.

Nun erinnerte sie sich an unsern älteren Bruder und an unsern Vater.

Sie rief nach ihnen, und sie kamen herbei.

Sie setzten sich mitten im Himmel nieder.

Darauf fragte sie sie: ,Was denkt ihr ? -

,Mag es so sein." -

,Ich denke so. In diesem Punkte meine ich folgendes:

Für das Wasser werden sie sorgen; damit werden sie die Erde bewässern.

Es werden wachsen: Bäume, Gras und Kräuter. Das meine ich."

Darauf sprach sie weiter zu ihnen.

,Das sage ich, ich mache die Dämonen.

Das sage ich, wenn es euch so gefällt? -

,Natürlich! so gefällt es uns.'

So sprach unser Vater, unser älterer Bruder gleichfalls sprach so: sie endeten.

Nun sprach sie: ,Ich will sie machen' (S. 57)."

Diese Dämonen werden in erster Linie alle als Regendämonen angesehen, anscheinend weil die Regenzeit, die wenig über drei Monate dauert,

1) Der Laut $x$ entspricht dem deutschen $c h$ in sich. 
die allergrößte Wichtigkeit für ihre Ernährung hat. Die Dämonen sind also in erster Linie Wolken, Wasser und Regen und werden entsprechend aus dem dieses symbolisierenden Material, ungesponnener Baumwolle, angefertigt. Es sind aber auch die Sterne darunter verstanden, während die Dinge der Erde, z. B. Berge, Felsen, die, nach dem Vorbild der benachbarten und nahe verwandten Huichol zu urteilen, auch darunter gemeint sind, noch gar nicht in Betracht kommen können, weil die Frde erst später geschaffen wird. Die Erdschöpfung geschieht nämlich lediglich aus dem Grunde, weil die geschaffenen Dämonen auf die Dauer nicht zufrieden sind, daß die Erd- und Mondgöttin sie ins Urmeer gesetzt hat. Sie reicht ihnen ihre eigenen Haare hin und erhebt die daran Angeklammerten an den Himmel, wo sie sie aufhängt. Auch dieses Zustandes sind sie schließlich müde, worauf die Erdgöttin sie auffordert, an ihrem eigenen Leibe zu suchen. Als sie dort Erde ergreifen und diese ihr einhändigen, legt der Morgenstern auf ihre Weisung seine Pfeile kreuzweise übereinander und bindet sie im Mittelpunkt mit einer Schlange zusammen. Um diese legt sie spiralig ihr eigenes Haar, das sie ausreißt, und oben auf das Ganze die Erde, die die Regendämonen an ihrem Leibe ergriffen haben, und die das „Fleisch der Dämonen" genannt wird. Nun treten sie darauf, und die Erde ist fertig. Die Göttin läßt nun auf ihr Steine, Bäume, Gras, Wasser und alle Tiere und auch die Menschen.

Diese Darstellung ist im einzelnen wichtig. Schon bevor die Erde geschaffen ist, wird das Urmeer die Erde genannt. Aus ungesponnener Baumwolle, d. h. aus Wasser sind die Regendämonen gemacht, und der Stoff, den sie an ihrem Leibe ergreifen und der ,Fleisch der Dämonen“ und zugleich Erde genannt wird, ist natürlich wiederum Wasser. Die Schlange, mit der der Morgenstern seine Pfeile zusammenbindet, ist gleichfalls die Verkörperung des Wassers und symbolisiert die schwarze Nacht, die der. Morgenstern mit seinen Pfeilen erlegt. Würde er das nicht tun, so würde eine Flut hereinbrechen. Endlich sind auch die Haare der Göttin, an denen sie die Dämonen an den Himmel hebt, und die sie dann spiralig um die Pfeile flicht, das Symbol des Wassers. Das geht aus dem das ganze Gesicht der Erdgöttin wie ein Backen- und Schnurrbart umrahmende Haar der Figur der Erdgöttin bei den Huichol hervor und aus der Gestaltung der als Symbol der Erde geflochtenen sternar'igen Figuren bei den Cora. Diese Figuren sind nämlich spiralig aus Baumwollfäden, dem Symbol des Wassers, umflochten in der Weise, wie die Schöpfungsgeschichte von den Haaren der Erdgöttin erzählt.

Die Göttin überschreitet also erheblich die Grenzen, die einem Heilbringer gesteckt sind. Ihre Taten sind nicht die Gestaltung der schon vorhandenen Erde, sondern eine vollständige Neuschöpfung, eine 
wirkliche Verkörperung eines großen, wenn nicht des bedeutendsten Teiles der Welt, und auch das Dalassen der Menschen auf der Erde bedeutet eine Schöpfung. Der Sonnengott gibt zwar seine Einwilligung dazu, sonst hat er aber nichts mit der Sache zu tun. Das erinnert sehr an die Tendenz der Kágaba, ihrer Allmutter einen Gatten aus einem der vier Urahnen zu geben, der ihr vorher mitunter den Auftrag gibt, bevor sie etwas ausführt.

Wir müssen die Erdschöpfung aber auch naturmythologisch bewerten. Wie wir sahen, besteht die Erde wie die Regendämonen, aus deren Fleisch die Erde in der Hauptsache gestaltet wird, aus wässerigen Stoff. Alles das hat die Mond- und Erdgöttin geschaffen, d.h. sie verkörpert alles. Weshalb besteht also diese Göttin aus wässerigem Stoff? Daß die ganze Erde aus Wasser besteht, dafür liegt in der Erde kein zureichender Grund. Auch das Urmeer ist, da es schon die Erde (ťăánaka) genannt wird, bevor noch die Erde geschaffen ist, eher bereits als die Substanz der Göttin aufzufassen. Und es ist zu bemerken, daß der ausschließliche Ausdruck für die Welt mit Einschluß der Gestirne derselbe ist wie der für die Erde (tšänaka). Es ist also sehr wahrscheinlich, daß die sog. Mond- und Erdgöttin das Wesen der ganzen Welt als Wasser in sich schließt. Wir kommen daher zu dem Schluß, daß das Wasser als Bestandteil der Göttin vom Dunkelmond, dem Anfangszustand der Göttin, herrührt, und daß aus dem Dunkelmond die ganze Welt ebenso hervorgeht wie bei den Uitoto.

Wie bei den Uitoto ist der Dunkelmond das Wasser, das die Flut verursacht. Der Flutmythus, soweit er für uns in Betracht kommt, lautet so:

„Vor langer Zeit geschah es, daß die Welt überschwemmte. Fin Mann legte ein Feld an. Des Morgens rodete er, und am andern Tage standen (die Bäume) wieder da. ,Was ist es, das (dieses) verursacht? Da spähte er danach aus: eine Frau steckte ihren Stock unter sie und richtete die Bäume auf. Dann standen sie. ,Weshalb hebst du sie auf ?' ,Ja, ich sage dir: rode nicht, die Welt wird zugrunde gehen. Was du tun sollst, (ist dieses): suche einen großen Baumstamm und höhle ihr aus. Suche eine junge Hündin und Kürbisstiele (als Brennmaterial). Gehe hinein und decke ihn gut zu. Lege die Kürbisstiele und das Fever hinein. "Das tat er. Er bearbeitete den Baumstamm und setzte die Hündin binein. Er schloß die Kürbisstiele ein, das Feuer und zugleich einen Schreivogel. So deckte er sich mit Lehm zu. Darauf überschwemmte die Welt. Er (d. h. der Baum) bewegte sich, (das Wasser) hob ihn in die Höhe, und er stieg aufwärts. Dann kam er auf der Himmelsebene an. Am fünften Tage langte er am Himmel an, au sechsten Tage stieg er abwärts, ebenfalls fünf Tage lang. Darauf sank (das Wasser), und die Erde begann ein klein wenig zu trocknen. 
Nun deckte er (den Baumstamm) etwas ab: ein wenig brannten noch die Kürbisstiele . . “" (S. 277f.)

Bei den benachbarten Huichol wird noch folgendes hinzugefügt: Die Frau wird als die Erd- und Mondgöttin bezeichnet, es wird außerdem noch Mais und andere Aussaat mitgenommen, und die Göttin setzt sich oben auf den Baumstamm. Sie machen eine Nachbildung dieses ausgehöhlten Baumstammes zur Regenzeit und setzen sie aus, damit nicht eine neue Flut komme. Eine solche Nachbildung habe ich mitgebracht: ein regelrecht ausgehöhlter kleiner Stamm von etwa $23 \mathrm{~cm}$ Länge, mit je einem Deckel an beiden Enden verschlossen, und obenauf ist eine aus Holz geschnitzte kleine Mondsichel angebracht.

Hier ist also der hohle Stamm der Dunkelmond ähnlich wie die in Gestalt eines ausgehöhlten Baumstammes gearbeitete Signaltrommel der Uitoto, die Flut ist das von dem Dunkelmond ausgehende Wasser, das Feuer im Innern des Baumstamms der Kern für die neu herauskommende Mondsichel, die Nachbildung der Mondsichel ist die oben daraufsitzende Göttin, die als neu hervorgekommen aus dem Dunkelmond aufzufassen und identisch mit dem geretteten Menschen und dem schließlich noch ein wenig glimmenden Feuer ist. Die Zauberanalogie liegt darin, daß die oben angebrachte Mondsichel das glückliche Ende der aus dem Dunkelmond entstandenen Regenzeit und Trockenheit und Fruchtbarkeit der Erde ohne neue Flutkatastrophe sichert.

Nachdem so ein neuer Beweis für die ursprüngliche Wassernatur der Göttin, die die Welt aus dem Wasser geschaffen hat, erbracht ist, müssen wir zugeben, daß der Sonnengott gegenüber der Erd- und Mondgöttin in der Weltschöpfung versagt hat und insoweit die letztere als Erscheinung der höchsten Gottheit anzusprechen ist. In dem Weltbild, das die Cora in der auf dem Altar stehenden Kürbisschale der Göttin darstellen, ist ihr Wohnort demnach in der Mitte angegeben. Da in dem einen Dorf der Cora, San Francisco, von dem Sonnengott so gut wie gar keine Rede in den Gesängen und Mythen ist und auch der Mondkult dort dem Sonnenkult in einem andern Dorfe, der Mesa, entgegengesetzt wird ${ }^{1}$ ), so ist zweifellos, da $\beta$ die Sonne erst später durch Übertragung zu ihrer Stellung bei den Cora gekommen ist.

Untersuchen wir nun, wie es mit der Welterhaltung durch den Kult oder das Wort ist, das der Sonnengott und die Mondgöttin den Menschen geben. An einem Feste, dem des Erwachens, das besonders zum Wohle der Kinder gefeiert wird, werden im ersten Gesange verschiedene Umläufe des Sonnengottes beschrieben, bis er wieder zum Zenit emporsteigt. Und dann fährt der Gesang fort:

1) Die Nayaritexpedition I., S. LVIII. 
„Hier angelangt denkt er daran, daß er das Fest des Erwachens feiern Er denkt und erinnert sich seiner Erde. [werde.

Hier sind gegenwärtig seine Worte, die er uns, seinen Kindern geben Damit wir in ihnen leben and bestehen auf der Welt. [wird, Schon sind hier gegenwärtig alle seine Worte, die er bestimmt und hier gelassen hat.

Hier lie3 er seinen Kindern seine Gedanken...“ (S. 2).

In einem andern Gesange desselben Festes werden Bedenken ausgesprochen, daß die Zeremonien des Festes, die das Spiel der Gottheit genarint werden, infolge der geringen kultischen Kraft der Menschen wirksam sein könnten, und daß es deshalb besser sei, einfach nach Hause zu gehen:

„... Schande bereiten wir unserem Vater, Schande machen wir seinen Worten.

Unehre bereiten wir unserer Mutter und ihren Worten.

Ist es wirklich sein Spiel? Immerhin ist es doch ein Akt des Gehorsams gegen ihn.

Deshalb, meine jüngeren Brüder, laßt uns zu unserer Hütte an den Nelkenbäumen gehen.

Schon haben wir die Worte unseres Vaters zuschanden gemacht.

Doch mag es so sein! Fürwahr, er hat uns so ausgestattet. Er allein Ewig ist er da. Erhaben sind seine Worte. [besteht.

Er hat keine Mängel, wie sie bei uns vorhanden sind ..." (S. 20).

Obwohl hier der Sonnengott offensichtlich als Quelle des Kults erscheint, wird dasselbe in einem andern Gesange auch von der Mondgöttin gesagt:

„.. . So gibt sie uns Leben, nämlich ihre Worte ..."

„... Seht den Häuptling, den wir zum Vater haben.

Dieser ist dein Wort (d.h. verkörpert als oberster Priester das Wort der Göttin).

Gib ihm ein wenig Leben mit deinem Lebenswasser.

Gib ein wenig dein Leben dem stellvertretenden Häuptling.

Gib ihm auch Leben.

Diese (beiden) sind deine Worte während der Regenzeit, du meine Mutter ..." (S. 245).

Was den Kult gegenüber diesen beiden Gotheiten betrifft, so haben wir nicht nur stille Verehrung und Gedenken, wie bei der Allmutter der Kágaba und dem Urvater der Uitoto, sondern direkte Anrufungen um Wohlwollen, Gnade und Hilfe. In der Fortsetzung jenes Gesanges, in dem vom Spiel des Sonnengottes die Rede ist, das die Menschen nicht wirkungsvoll verrichten können, heißt es: 
„So bitten wir nun und flehen zu unserem Vater:

Er verzeihe uns aus eigenem Antriebe, daß wir seine Worte verdreht

Daher verlasse er uns nicht und sehe gnädig auf uns. [haben.

So bitten wir denn, er möge auf uns ferner schauen.

In diesem Sinne bringen wir unsere Worte vor ihn.

So sei es: er helfe uns, wenn er gnädig auf uns schauen mag.

Wo nicht, was wird er tun? Wir sind völlig in seiner Hand.

So bitten wir, und so wird er es vollenden ..." (S. 20).

Das ,Wort" hat daher nicht ausschließlich die Bedeutung als Mittel zur Beeinflussung der Naturdinge, sondern wird ganz im gewöhnlichen Sinne einer Religion zu einer Art Gebet. Das ist auch gegenüber der Erd- und Mondgöttin der Fall, wie aus einem ihr gewidmeten Gesange desselben Festes des Erwachens hervorgeht, das sie im Sinne der von ihr ausgehenden Welt- und Menschenschöpfung als alleiniger Erhalter feiert:

„Schon haben wir in ihr das Leben. Hier bestehen wir, wie sie es bestimmt hat.

Sie allein hat es angeordnet, $\mathrm{da} B$ wir in ihr das Leben haben.

Hier bestehen wir, wie sie es bestimmt hat. Sie allein hat es angeordnet.

Hier ließ sie uns. Geborene nannte sie uns.

Hier sind wir. Mögen wir wissen, wie wir hier sind.

Wir sprechen zu ibr mit ihren Gedanken.

Möchte sie in ihnen uns gnädig ansehen, wie wir es wünschen!

Während wir hier bleiben, werden wir fürwahr ihr Schande bereiten ${ }^{1}$ ) auf ihrer Erde.

Wir möchten hier bitten: möchte sie zu uns, ihren Kindern, sprechen! Was wird sie tun? Doch stattete sie uns hier so aus und gab uns Worte [der Sünde] ${ }^{2}$ ).

So sind wir hier und sprechen als Sünder..." (S. 6f.).

Ausschlaggebend für die primäre Bedeutung der Mondgöttin als oberste Gottheit sind wieder die Verhältnisse in dem Dorf San Francisco, wo sie im Gebet als „Mutter und Vater" angerufen und der Sonnengott überhaupt nicht erwähnt wird.

„Bittet die, die wir zur Mutter haben,

daß sie kein Übel schicke, und daß uns nichts zustoße.

Meine Brüder, bei Tag und bei Nacht,

nach allen Seiten bitten wir die Gottheit, die wir zur Mutter und die wir zum Vater haben..." (S. 263).

Ebenso in einem Gebet, wo sie um Heilung einer Krankheit angerufen wird und die Einheit der Person aus dem Pronomen ,deiner" hervorgeht:

1) In dem vorher erörterten Sinne.

2) D. h. unvollkommene Worte, da die Menschen unvollkommen sind. 
„Gott, du meine Mutter, du mein Vater, ich erinnere mich deiner . . ."

(S. 264).

Das Gebet schließt dann auch wieder: ,So sei es, Gott, du meine Mutter..."

Solche Bitten, die auch besondere Wünsche, z. B. um Regen, aus. drücken können, werden nicht nur an die beiden Götter, sondern auch an ihren Sohn, den Morgenstern, und an die Verstorbenen gerichtet, die nach dem Tode zu Regen bringenden Gottheiten werden und in die Gemeinschaft der drei vorher genannten gelangen. Die Verstorbenen nehmen also gleich dem Morgenstern, bei dem sich das aus seiner Natur als Heilbringer erklärt, eine Vertrauensstellung ein, während das bei den übrigen Naturwesen, die deshalb Dämonen genannt werden müssen, nicht der Fall ist. Man findet daher ötters in Gebeten alle vier in der Anrede vereint: ,Gott, du mein Vater, du meine Mutter, du mein älterer Bruder, meine Alten! Aber auch an die Unterweltsgöttin T'éteuan, eine Form der Mondgöttin, und ihre Söhne, die Flußgötter, richtet man Gebete, daß die letzteren den Menschen nicht Krankheiten verursachen, wenn sie ins Wasser gehen. Tétewan wird dabei als Vermittlerin angerufen. Die Gewässer der Unterwelt reichen nämlich von der Unterwelt bis zur Erdoberfläche, und deshalb sind die Flußgötter die Söhne Têtewans.

Aus diesen Gebeten geht klar hervor, daß sich die Gottheiten der Cora, also auch der Sonnengott und die Mondgöttin, von den uns gewohnten Gestalten jeder etwas höherstehenden Religion nicht unterscheiden, und das sehen wir auch an den ihnen gewidmeten Opfergaben, nämlich Maismehl, Tabak, Federstäbe brw. Pfeile mit angehängten Federn, mit ungesponnener Baumwolle oder Wolle und mit den schon erwähnten Figurensternen, Abbildern der Erde. Die Federn und die z. T. gefärbten Fäden der Sterne, die z. B. für die Sonne rot sind, entsprechen dem Naturgegenstand, den sie verkörpern, indem die betreffenden Vögel ihnen zugehören, d. h. Abbilder von ihnen sind. Tabak und ungesponnene Baumwolle dienen zum Hervorbringen von Wolken bzw. sind Wolken und Wasser. Alles in allem sollen die Dinge das Wesen der Götter stärken, damit sie ihre Obliegenheiten erfüllen können. Das ergibt sich klar aus den Angaben der Huichol. In den Gebeten der Cora ist aber nur ausgedrückt, daß sie eine Gabe sind, eine Art Bezahlung.

"Gott, du mein Vater, wegen eines Anliegens kommen wir her, hiermit (d. h. mit dieser Opfergabe) erinnern wir uns deiner, unsere Mutter ..." (S. 124).

Oder:

„,Hier komme ich, Tšakan (der Wassergott). Du fügst mir Schaden zu. Hier bringe ich dir etwas: damit bitte ich, du möchtest mir nicht schaden. Hier ist Maismehl und ungesponnene Baumwolle, das gebe ich dir . . ."

(S, 134). 
Bei den Verstorbenen aus den letzten Generationen, die man um Vermittlung bei den drei Gottheiten Sonne, Mond und Morgenstern und den Alten angeht, daß sie den Bittenden noch einige Zeit des Lebens auf Erden schenken möchten, ist es natürlich, wenn das ihnen gegebene Maismehl als Nahrung gegeben wird. Dieser Gedanke tritt jedoch auch bei den Gottheiten hervor.

„.. . Schauet also darauf (auf das Maismehl) hin: hier übergebe ich euch meine Worte.

Ihr wollt nicht alles hören: hier gebe ich euch ein wenig (Maismehl). Davon mögt ihr leben und bestehen, wo euch ließ unser älterer Bruder, unsere Mutter und unser Vater ..."

(S. 133).

Auffallend ist nun, daß die Sternfiguren, die die Erde darstellen und eigentlich nur ihrer Verkörperung, der Mondgöttin, zukommen, allen genannten Gottheiten, auch dem Sonnengott, dargebracht werden, was auf eine spätere Übertragung auf die andern schließen läßt. Doch mư man dazu noch abwarten, was dieselben Figuren bei den Huichol bedeuten.

Die höchste Gottheit der Cora, die Mond-, Erd- und Maisgöttin, unterscheidet sich also von ihrem männlichen Kollegem bei den Uitoto nur dadurch, daß die Weltordnung, die sie den Menschen in dem Wort gibt, durch direkte Anrufung der Göttin durchbrochen ist. Auch der Urvater der Uitoto erscheint ja in den Gewächsen und in den Frïchten. Indem sie als Naturding tätig in das Leben der Menschen eingreift, konnte ein Vertrauensverhältnis zwischen diesen und ihr eintreten, das von der natürlichen Güte und Gerech. tigkeit der sonst in vornehmer Zurückhaltung herrschenden höchsten Gottheit seinen Ausgang nimmt. In der Tat bedeutet sie den Cora alles, während der Sonnengott weniger als eine höchste denn als eine fremde Gottheit zurücktritt.

Die Göttin hat nicht nur die Menschen geschaffen, sondern erhält sie auch, indem sie ihnen und den Göttern oder Dämonen ihr Lebenswasser spendet, das auf den Nachthimmel, im letzten Grunde aber auf das Wasser des dunkeln Mondes zurückgeht. Daß dagegen in einem Gebete die Vierheit Vater, Mutter, älterer Bruder und die Alten zur Sicherung der Gesundheit angerufen werden und dabei der Sonnengott als erster besonders hervorgehoben wird (S. 128), dürfte als das Bestreben aufzufassen sein, die Göttin durch die männliche Gestalt des Sonnengottes zu ersetzen. Die Göttin ist nicht weniger die Göttin der Erde wie des Nachthimmels, den ihre Kürbisschale mit dem Weltbilde darin auf dem Altar im besondern symbolisiert. Die Sterne am Himmel sind die Blumen in ihrer Kürbisschale, wie die Gesänge besagen, und das Wort für Nacht bedeutet auch das Wasser und die Regenzeit. Immer wieder 
wird besungen, wie sie ihr Lebenswasser spendet und darum gebeten wird. Dadurch bleiben die Menschen am Leben. Aber sie hat auch allein Gewalt über den Tod, der die notwendige Ergänzung der Lebensfürsorge bildet. Im Gesang an die Grillen werden diese angeredet:

„Hürimu (,das Leben') erblickt ihr, die dort unter unseren Füßen lebt, Sprechet hier hinab, daß sie uns nicht ergreife und hinabziehe (in die Erde)" (S. 221).

In einem Mythus von der Entstehung des Todes ist es zwar der Sonnengott, der die Frage erörtert, was mit den Menschen werden soll, wenn sie alt werden. Schließlich entscheidet aber die Eidechse:

„Sie sollen sterben. Sie werden geboren und sollen hier unten verschwinden in der Erde. Die wird sich von ihnen nähren. Auf der Erde sollen sie sich ihrer bedienen, und die Erde ihrerseits wird sie verzehren. Hier wird hervorkommen, was sie säen. Was hier alles aufsprießt, davon leben und bestehen sie." (S. 145).

Andererseits herrscht die Anschauung, daß der Kolibri, der Bote der Sonne, wenn er an der Tür eines Hauses zwitschert, den Tod eines Insassen ankündigt. Das wird auch in einem Mythus ausgesprochen, in dem die Sonne ihren Boten Kolibri aussendet, um einen Hüttenbesitzer zu benachrichtigen, da $B$ er sterben müsse.

Die Neigung, die weibliche höchste Gottheit durch eine männliche, eben den stammfremden Sonnengott zu ersetzen, offenbart sich auch darin, daß dieser z. B. das Fest des Erwachens zu feiern beschließt und dann beim Untergehen im Westen die dort wohnende Mondgöttin, den Mais, Nấsisa auffordert: „Wohlan, du sollst sie zum Singen veranlassen", worauf sie als kleines Mädchen von 3-4 Jahren auf dem Festplatz erscheint und alles leitet. Ihre Kraft in dieser anscheinend hilflosen Jugendlichkeit, in der sie an allen Festen erscheint, kommt wohl von ihrer gewaltigsten Erscheinung, der neuen Mondsichel, die den Wechsel auf Erden, die Fruchtfolge, hervorruft.

Wenn am Anfang der Regenzeit die meisten Bäume Früchte tragen und die Zikaden ohrenbetäubend zu zirpen beginnen, dann wird gesungen und mimisch dargestellt, daß die Götter dieses Tier am Himmel mit den Blüten und Früchten der Erde schmücken und zu den Menschen senden, damit es alles unter sie verteile. Nach der Ernte aber sammelt die Göttin selbst wieder auf der ganzen Welt alle Blüten der Früchte in ihre Kürbisschale, und ihr Sohn, der Abendstern, der an Stelle aller Sterne die. Vegetation verkörpert, bringt sie wieder an den Himmel, wo dann alle Blumen der Erde leuchten. Wie die Seele des Urvaters der Uitoto als Seele der Früchte nach der Ernte wieder an seinen Wohnsitz in dio zweite Unterwelt entweicht, so sammelt sich bei den Cora wieder alles am Nachthimmel. Und dieser ist das Spiegelbild der Unterwelt: 
„... unserer Mutter Tétewan, die in der Unterwelt lebt.

Dort wohnt sie, wo alle Dinge sind, die hier zum Vorschein kommen auf der Erde" (S. 68).

Die Götter aber, die die Zikade schmücken, der Blumen- und Maisgott Sautari, der Sohn der Göttin, und die.Unterweltsgöttin Tétewan sind nur Teile des Wesens der Mondgöttin, die selbst der Mais ist und als deren

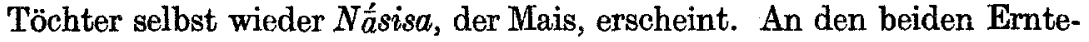
festen des Maises, kurz nach der Regenzeit, wenn die jungen Maiskolben gekocht werden, und später, wenn der harte Mais im Feuer geröstet wird, übergibt sie selbst ihren Sohn, den Mais, dem Feuer, das ihn tötet, und ,es weint unsere Mutter über ihren Sohn, weil man ihn getötet hat " (S. 110). Im nächsten Gesang erscheint er aber wieder am Himmel bei seiner Mutter und spricht:

„Ich bin nicht gestorben.

So weiß ich es (einzurichten): ich werde sie täuschen.

Sie erscheinen (nur einmal), meine jüngeren Brüder.

Sterben sie nicht wirklich für immer?

Ich dagegen sterbe niemals.

Ich werde dauernd erscheinen, ich werde hier bestehen ..." (S. 111).

Indem er also hier die Dauer im Wechsel der Natur aufstellt und sie in Gegensatz zu dem einmaligen Erscheinen der Menschen auf Erden setzt, bietet der ganze Vorgang nur eine Wiederholung des schon geschilderten Kreislaufs der Baumfrüchte. Alles ist aber nur eine Darstellung des Wesens der Göttin selbst, die eigentlich selbst dieses Schicksal erleidet. Aber wie sie die Welt schafft, die sie verkörpert, so regiert sie deren Wechsel, der sich an ihrer Person vollzieht. Und der Kult, der diese Vorgänge unter ihrer persönlichen Leitung regelt, beruht auf ihren Worten, die sie den Menschen gegeben hat, auf der Weltordnung, die sie selbst verkörpert.

Wo aber Gottheiten einen mehr selbständigen Tätigkeitsbezirk zu haben scheinen, da herrscht sie über sie souverän, wie wir es noch bei dem höchsten Gott der Botokuden kennen lernen werden. Wir wissen bereits, daß sie den Adler, den Lichthimmel, zu seinem Berufe am Himmel anstellt. Sie setzt ihre Söhne, den Morgen- und Abendstern, zu Wächtern des Himmels ein. Diese bilden nun die Vermittler zwischen der Göttin und den zahllosen nicht mit Namen genannten Göttern der Weltrichtungen und andererseits zwischen der Göttin und den Menschen. Dabei stellt der Abendstern mehr die passive Natur der Sterne und der Vegetation dar, während der Morgenstern der aktive Vermittler ist und vor allem als ein richtiger Heilbringer den Kult bei den Menschen einführt. Es wird geschildert, wie diese ursprünglich vergeblich versuchen, ein Fest zu veranstalten, wie es ihnen nicht gelingt, den primitiven Altar zu errichten, bis dann der Morgenstern in Gestalt 
eines kleinen Knaben erscheint und kraft seiner übermenschlichen magischen Fähigkeiten alles bis ins einzelne bewerkstelligt. Noch heute tritt er in dem einen Dorfe, Jesus Maria, als ein solcher Knabe neben der Mondgöttin auf und hilft ihr in allem.

Zwei Aufgaben hat er aber selbständig zu erledigen als Vorläufer der Sonne. Einmal tötet er des Morgens mit seinen Pfeilen die Sohlange der Nacht, die das Wasser verkörpert und dann vom Adler, dem Lichthimmel, verzehrt wird. Wenn er das nicht täte, so würde eine Flut hereinbrechen, wie sie tatsächlich in einem Mythus geschildert wird. Hier ist eine Umwandlung der ursprünglichen Idee des Dunkelmondes als Wasser und der Mondsichel zugunsten der Sonne festzustellen. Zweitens erlegt er mit seinen Pfeilen die als Hirsche aufgefaßten Sterne. Beide Szenen werden dargestellt. Die Sonne selbst aber wird erst dadurch geschaffen, daß die Vorfahren einen Knaben ins Feuer werfen, ganz wie bei den Uitoto ein Vorfahr verbrannt wurde, um zur Sonne zu werden. Bei diesen erlangte er keine besondere Bedeutung dadurch, obwohl Andeutungen vorhanden sind, daß er ein Kollege des Urvaters und Schöpfer hätte werden können. Bei den Cora jedoch ist er später neben und über die höchste Gottheit, die Mondgöttin, gesetzt. Thre Priorität hat sich aber, wie die vorhergehenden Ausführungen beweisen, noch klar erkennen lassen.

Das Lehrreiche an diesem Typus der höchsten Gottheit ist demnach, daß man ihre Eigenschaften nicht aus einem der von ihr verkörperten Naturdinge ableiten kann und auch die Beziehungen der verschiedenen Naturdinge im Wesen der Göttin: Mond, Nachthimmel, Sterne, Erde, Unterwelt, nicht aus diesen heraus versteht. Es ist schon öfters an anderen Stellen von mir hervorgehoben worden, daß an dieser Göttin das Primäre nicht der Mond, sondern der Nachthimmel sei. Die Wahrheit ist nach den vorstehenden Untersuchungen, daß der übergeordnete Begriff der höchsten Gottheit als Verkörperung der Welt die Beziehungen der einzelnen Naturdinge zueinander bestimmt. Den dunkeln Mond kann man z. B. nur dann mit dem dunkeln Erdinnern und sein Wasser nur dann mit der Unterwelt und dem Wesen der Göttin Tétewan als Wassergottheit gleichsetzen, wenn die Schöpfungsidee aus dem Wasser des dunkeln Mondes bereits gefaßt ist, $d$. h. nachdem die Schöpfungsgottheit als Verkörperung der ganzen Welt bereits Eingang gefunden hat. Nicht das Einzelne geht stets im Denken voraus, sondern ein Gesamteindruck vermittelt einen Gedanken, der dann in das Einzelne verfolgt wird. Ebenso sehen wir, wie die beiden Brüder, der Morgenstern und der Abendstern, die die Cora für zwei Personen halten, öfter als Vertreter sämtlicher Sterne gelten. Man darf daher nicht strenge von den einzelnen Gestirnen ausgehen, um das Wesen einer entsprechenden Gottheit zu verstehen, sondern muß im Auge behalten, daß die 
Fixierung in einem bestimmten einzelnen Stern nicht das Primäre zu sein braucht.

\section{Die alten Mexikaner ${ }^{1}$ ).}

Am besten zeigt auch die mexikanische Religion die Unmöglichkeit, daß die Sonne bei den verwandten Cora ursprünglich mit der obersten Gottheit verbunden wurde, denn so mächtig sie ist, ist sie doch erst später von den Göttern geschaffen, und ist ihrerseits alles eher als eine schöpferische Gottheit, wenn sie auch später Mais und alle Dinge hervor. bringt. Aber auch der Mond entstand erst später. Aber trotz dieser bestimmten Angabe tragen sämtliche Gottheiten mit Ausnahme des Sonnengottes Tonátiuh lunare Züge und haben eine nächtliche Natur, sowohl die männlichen wie die weiblichen. Die meisten von ihnen sind als nächtliche Gestirndämonen genannt, die in der Urheimat Tamoanchan, dem Hause der Geburt, als Kinder des höchsten Götterpaares Tonacatecutli und Tonacaciuatl geboren wurden. Weil sie dort Zweige abbrachen, wurden sie von Tonacatecutli verjagt und kamen zur Erde und in die Unterwelt herab. Tamoanchan selbst wird durch einen umgebrochenen, blutenden Baum mit Blüten dargestellt. Also wird schon die Urheimat als der vergehende, sich in Sterne auflösende Mond charakterisiert. Sie stellt, wie der Jukabaum der Uitoto alle Früchte der Erde in seinem Gipfel trägt, das Land der Fülle und des Wasserreichtums dar, und wird wie dieser umgehauen. Auch vom Jukabaum der Uitoto schneidet man zuerst Splitter und bricht Zweige ab, was sein allmähliches Vergehen als Mond kennzeichnen soll. Ganz ebenso brechen die Götter in Tamoanchan $Z$ weige ab und zerstreuen sich mit dem vergehenden Monde, den sie verkörpern.

Dadurch ist auch das höchste Götterpaar der Mexikaner von vorn. herein in Beziehungen zum Monde gebracht, doch vermischt es sich nicht in der Weise mit einem einzelnen Naturding, daß sein Wesen mit ihm verschmilzt. Im Gegenteil wird es so unabhängig und abstrakt wie nur möglich aufgefaßt, und seine eigentliche Wohnung, der oberste Himmel Omeyocan, „der Ort der Zwei" wird nur mit Tamoanchan identifiziert, da beides der Ort der Geburt ist. Nur durch ihre andern Namen Citlallatonac und Citlalin icue, "Sternensonnenglanz" und ,die mit dem Sterngewande", werden sie der nächtlichen Seite des Himmels zugewendet und mit der Milchstraße identifiziert, da Citlalicue die Bezeichnung für die Milchstraße ist. Es ist bereits darauf hingewiesen worden, daß die Zweiheit des höchsten Gottes auf soziale Verhältnisse zurückzuführen ist. In dem Paar haben wir in der Tat das höchste Wesen der kulturarmen Völker zu sehen, es ist also durchaus nicht aus einer Teilung der

1) Siehe als Unterlage Eduard Seler, Codex Borgia, Berlin 1904, I, besonders S. 77-81 über Tonacatecutli und I, S. 82-87, über Quetzalcoatl. 
Welt in einen männlichen Teil, der Himmel, und einen weiblichen, die Erde erwachsen, sondern eine bloße Auffassung als Ganzes. Und die Bezeichnung ihres Wohnsitzes als Ort der Zwei und ihre eigenen Beinamen als Ometecutli, Herr der Zwei, und Omeciuatl, Herrin der Zwei, weisen lediglich darauf hin, daß sie, jeder für sich, die Menschheit und ihre Erhaltung durch Fortpflanzung verkörpern, wie ja auch in den Bilderschriften neben Tonacatecutli allein ein Menschenpaar in geschlechtlicher Vereinigung dargestellt ist.

Alles an Tonacatecutli weist die typischen Züge eines höchsten mit Naturdingen unvermischten Gottes auf. Deshalb wird von ihm, wie von der Allmutter der Kágaba, keine Schöpfungsgeschichte erzählt und nur erwähnt, daß er die Welt geschaffen habe. Er verkörpert eben als Herr des obersten Himmels die ganze Welt und wird als solcher Schöpfer, Herrscher über alles und Herr der Erde genannt. Auch der Ausdruck "der erste Mensch" kommt ihm als Verkörperung der Menschheit mit Recht zu. Tonacatecutli selbst heißt der Herr unseres Fleisches, unseres Körpers, der aus Mais besteht, und wird daher oft als Gott der Lebensmittel übersetzt. Darin drückt sich die Erhaltung seiner Geschöpfe aus und ebenso darin, daß man von ihm sagte: „Von diesem großen Herrn hänge das Sein aller Dinge ab und auf seinen Befehl komme von dort (vom obersten Himmel) der Einfluß und die Wärme, vermöge deren die Kinder sich in dem Leibe ihrer Mutter erzeugen." Von dem Neugeborenen sagt man in einem Gebet bei der Taufe: „Du bist gebildet worden an dem Orte, wo der große Gott und die große Göttin, die über den Himmeln sind, weilen. Es hat dich gebildet und erzeugt deine Mutter, dein Vater, Omeciuatl, Ometecutli, die Himmelsfrau, der Himmelsmann."

Aber man betete nicht zu ihm, noch opferte man ihm, weil ex keine Opfer haben wolle, wie ein alter Berichterstatter sagt, der uberhaupt das Wesen dieses Gottes scharf den andern Göttern oder Dämonen der Mexikaner gegenüberstellt. Er hatte auch keine Tempel, sondern man gedachte nur seiner in Dankbarkeit. Obwohl er also die Welt geschaffen hat und für sie sorgt, so tut er es nur als die Verkörperung von allem, wozu auch die Erhaltung durch die in seinem Wesen liegende Welt. ordnung gehört. Es fehlt dem Bilde dieses höchsten Gottes Tonacatecutli jedoch der Zug, daß er den Menschen den Kult gegeben habe. Aus diesem Grunde haben die Mexikaner einen zweiten Schöpfergott aufgestellt, an dem aber weniger diese Eigenschaft als die andere hervorgehoben wird, daß er als Priester und König der prähistorischen Tolteken den Kult eingeführt habe, und zwar besonders die mannigfachen Arten der Bußübungen und Blutentziehungen, während er als Opfer nur Vögel, Schlangen und Schmetterlinge dargebracht habe, ganz im Gegensatz zu den Menschenopfern der historischen Zeit, die einem seiner Nach- 
folger zugeschrieben werden. Dieser Heilbringer ist Quetzalcoatl. Von ihm heißt es:

„Und man sagt, daß im Innern des Himmels er als Götter verehrte und anrief die Göttin mit dem Sterngewand, den Sternensonnengott, die Herrin und den Herrn unseres Fleisches, die sich in Kohle, die sich in Blut kleiden. Und er schrie hinauf, wie man erfuhr, nach dem Omeyocan, dem über dem neunfach verketteten ruhenden Himmel, und wie erzählt worden war, die dort ihre Wohnung hatten, die rief er an und verehrte sie in Demut und in Kümmernis."

Das Gebet wird ihm jedoch nur deshalb zugeschrieben, weil es wie bei den Cora auch bei den alten Mexikanern üblich war, Gebete an die Götter, abgesehen von Tonacatecutli, zu richten.

Mit der Bezeichnung eines bloßen Heilbringers kommen wir aber bei Quetzalcoatl nicht aus, obwohl er als solcher eine genaue Parallele zu dem Morgenstern der Cora bieten würde, da auch Quetzalcoatl als Mơrgenstern bezeichnet wird. Seine Eigenschaft als Schöpfergott verbietet das. Fs ist hier in Mexiko vielmehr der Fall eingetreten, daß einige der männlichen Hauptgötter, die, wie übrigens auch viele andere, als Söhne Tonacatecutlis bezeichnet werden und, wie erwähnt, vom nächtlichen Himmel ihren Ursprung nehmen, zusammen die Schöpfung vornehmen, weil sie Götter der Hauptstämme Mexikos sind. Es wiederholt sich hier nur der Vorgang wie bei den Cora, daß man das Bedürfnis hat, die Verkörperung der Welt mit ihren Schöpfér- und Erhaltereigenschaften einem kulterhaltenden Naturteile hinzuzufügen. Die Dämonen werden dadurch zu Göttern, insofern sie in ein Vertrauensverhältnis zu den Menschen treten, und das färbt auch auf die übrigen Naturdämonen $a b$, wie wir das schon bei den Cora sahen. Während aber bei den Cora und Uitoto nur ein Zusammenfallen von Schöpferidee and einzelnem Naturding in der Mondgottheit festzustellen ist, bleibt bei den Mexikanern die eigentliche Schöpfergottheit ohne Kult bestehen. Bemerkenswert ist, daß unter den Schöpfergöttern der Mexikaner gar keine weibliche Gottheit angegeben ist, obwohl es dort vermöge der vielen Stämme von Mond- und Erdgöttinnen im Naturstile der Coragöttin wimmelt. Das liegt an den sozialen Verhältnissen.

Als erster unter den Schöpfergöttern der Mexikaner wird Quetzalcoatl genannt ${ }^{1}$ ). Er wird aber auch allein als solcher erwähnt, obwohl dann nur wenige Einzelheiten seiner Tätigkeit hervorgehoben werden. Nur von dem Wesen dieses einen Gottes soll daher weniges mitgeteilt werden, da es unmöglich ist, alle in Betracht kommenden Gestalten hier zu analysieren. In dem allgemeinen Schöpfungsbericht wird von den Göttern

1) Siehe den Schöpfungsbericht in der Historia de los Mexicanos por sus pinturas in Icazbalceta Nueva Coleccion de documentos para la historia de Mexico. Mexiko 1891, III, S. $228 \mathrm{ff}$. 
das Feuer, eine halbe Sonne, die wenig leuchtete, ein Menschenpaar, der Gott der Unterwelt und seine Frau (d. h. die Unterwelt), die Himmel mit Ausnahme des schon bestehenden obersten, das Wasser und die Wassergötter und im Wasser ein großer Fisch cipactli und aus diesem der Herr der Erde (d. h. die Erde) geschaffen. Dieser trockene Bericht zählt also nur auf. Wir müssen aber annehmen, daß sie alles dieses in sich verkörpern, und dabei tritt die Wassernatur der Welt ein wenig hervor.

Nun heißt Quetzalcoatl Schlange mit (oder aus) den Federn des Quetzalvogels, und als solcher ist es erklärlich, daß er in verschiedenen Quellen als Federschlange, die im Wasser geht, als Herz des Wassers und als Nachtschlange ${ }^{1}$ ) genannt wird, denn er ist sekundär wie die Schlange der Cora, die des Morgens rom Morgenstern erlegt wird, die Nacht als Wasser bzw. primär der Dunkelmond als Wasser, wie wir ihn bei den Cora wie bei den Uitoto kennen gelernt haben. Deshalb wird er auch als hervorragendste Wassergottheit neben dem besonderen Regengott Tlaloc, den einst die Götter schufen, kultisch behandelt. Er wird Nacht und Wind [Youalli eecatl] ${ }^{2}$ ) wie sein Widerpart, der andere Schöpfergott Tezcatlipoca genannt, und sein Name ist neben Quetzalcoatl einfach: Wind. Es ist schwer zu sagen, ob diese Bezeichnung mit seiner ursprünglichen Natur als nächtliches Wasser zusammenhängt, wie auch der Ostwind tlalocayotl, ,der vom Wohnsitz des Regengottes Tlaloc 2)" heißt, oder ob der Name Wind seiner weiteren Auffassung als Morgenstern seinen Ursprung verdankt, denn auch der Morgenstern der Huichol Parikuta muyeka, "der vor Anbruch des Tages wandert", ist ein Gott des Windes und der Luft. Als Herrscher im Reiche Tollan wird er vertrieben, wandert nach Osten und verbrennt sich auf einem Scheiterhaufen am "Orte des Verbrennens" (Tlatlayan), im Lande des Schwarzen und Roten (Tlillan tlapallan), während seine Asche sich in Vögel mit schönem Gefieder (die Sterne) verwandelt und sein Herz als Morgenstern zum Himmel emporsteigt. Nach anderen verschwindet er im Meer des Ostens. Seler hat bereits das Verbrennen im Osten als den vergehenden Mond aufgefaßt und hat auch sonst manches Mondsymbolische an Quetzalcoatl vermutet ${ }^{3}$ ). Auch das Land der Roten und Schwarzen erscheint mir nun ein Symbol des Vergehens zu sein, wie es allein im Monde mit seinem hellen und dunkeln Teil dicht nebeneinander vorkommt. Überall in den mexikanischen Bilderschriften ist es das Symbol des Todes, und auch die Schilderung Tonacatecutlis mit der Bezeichnung ,der sich in Kohle kleidet, der sich in Blut kleidet", muß man als dem Mondbild entnommen ansehen. Schließlich ist auch sein

1) Yolcuat $=$ Youalcouatl. Siehe Seler, a. a. O., S. 83.

2) Historia de los Mexicanos, a. a. O., S. 228.

a) Seler, Gesammelte Abhandlungen, S. 334ff. 
Verschwinden im Meere des Ostens das Verschwinden des hellen Mondes im Meer des dunkeln Mondes.

Einiges von diesen Mondzügen findet sich auch in den Schöpfungstaten des Gottes. So schafft er die Menschen aus Asche ${ }^{1}$ ). Das ist bei den Uitoto immer ein Bild des dunkeln ausgebrannten Mondes, aus der die Menschen als Mondsichel hervorgehen. Nach anderen Quellen ${ }^{2}$ ) holt er die Totenknochen zur Menschenschöpfung aus der Unterwelt. Sie werden zermahlen und dann von Quetzalcoall und darauf auch von andern Göttern mit Blut aus ihrem Penis bzw. aus andern Körperteilen beträufelt. Auch das erscheint als die Belebung des dunkeln Mondes, symbolisiert in dem Totenknochen der dunkeln Unterwelt. Deutlicher wird dieses Bild dadurch, daß die Knochen in einer Edelsteinschale (chalchiuhapaztli) gemahlen werden, und aus solcher wie eine Höhle dargestellten Schale, die ebenso heißt, kommen auf dem Lienzo de Jucutacato die toltekischen Bewohner von Michuacan und überschreiten sofort ein Wasser, das Wasser des dunkeln Mondes. Es liegt hier wie bei den Uitoto und bei den "Sieben Höhlen" der mexikanischen Stämme und der Ursprungsinsel Aztlan der Azteken immer dasselbe Bild des mit der Unterwelt identifizierten Dunkelmondes vor, aus dem gleich der Mondsichel die Menschen kommen. Seler hat daher schon mit Recht das ganze Reich Tollan, das Land der Binsen, mit seiner Daseinsfülle als das Symbol des Mondes gedeutet. Auch das hinzugetane Blut der Götter ist nicht etwa nur als ein bisonderer Saft aufzufassen, sondern steht in der Farbe im Gegensatz zu dem Dunkeln, Toten des gemahlenen Knochens und bedeutet den Keim des hervorkommenden Lichts, sind doch die Schöpfer mit ihrem symbolischen Schöpfungsbild identisch. Es ist der schon erwähnte, allenthalben im Mexikanischen vorkommende Gegensatz des Schwarzen und Roten als Sinnbild des Vergehens und. Entstehens, des Verschlossenseins und Herauskommens.

Auch die Besorgung des Maises für die Menschen, die Quetzalcoatl zugeschrieben wird, entspricht dem Mondbilde. Als schwarze Ameise geht er zusammen mit der roten Ameise in den „Berg der Lebensmittel ${ }^{\text {l6 }}$ hinein und holt den Mais heraus, ähnlich wie Maiskörner und andere Samen aus dem ausgehöhlten Baumstamm nach der Flut mit dem geretteten Menschen bei den Cora und andern Stämmen wieder herauskommen. Wir haben also gerade im Mexikanischen wieder einige wenige, immer wiederkehrende Bilder wie schwarz und rot, Verschlossensein und Herauskommen, Tod und Leben, mit denen sie operieren, und man ist daher wieder versucht, solche Gegensätze ohne Beziehung zum Monde entstanden zu denken. Das erscheint mir aber, wie gesagt, unmöglich.

1) a. a. O., III, S. 46.

2) a. a. O., V, S. $185 \mathrm{ff}$. 
Wo Quetzalcoati die Schöpfung allein zugeschrieben wird, geschieht es in summarischer Weise: "Und solches sagten unsere Väter, unsere Großonkel. Sie sagten, daß uns machte, schuf und bildete, der, dessen Geschöpfe wir sind, unser Fürst Quetzalcoatl, und er schuf den Himmel, die Sonne, den Gott der Erde (d. h. die Erde)." Für die Erhaltung der Menschen ist er gleichfalls dauernd tätig, was aus den Worten der Verwandten an das neugeborene Kind hervorgeht: „Du bist gestaltet worden in dem höchsten Orte, wo die obersten Götter wohnen, über den neun Himmeln. Es hat dich gegossen wie eine Goldperle und geschliffen wie eine Edelsteinperle deine Mutter, dein Vater, die große Herrin, der große Herr und mit ihnen unser Fürst Quetzalcoatl." Seine Erhaltungstätigkeit ist also einfach an die des höchsten Götterpaares angeschlossen.

Es würde in diesem Zusammenhang mit der Frage der höchsten Gottheit von Bedeutung sein, wenn wir auch die Natur der übrigen nach und neben Quetzalcoatl hervortretenden Schöpfergötter analysieren und namentlich auch ihre Beziehungen zur Sonne feststellen würden. Wir würden dann erkennen, daß sich die Gedanken immer wieder um den nächtlichen Himmel und das Ergehen drehen, wie es im Monde sich ausdrückt, daß der Morgenstern als Vorläufer der Sonne und sein Widerpart der Abendstern eine Sonderstellung gegenüber dem Nachthimmel und Monde erhält, ohne daß seine Zugehörigkeit dazu aufgehoben wird, und daß die mit dem Mondlicht und den Sternen verbundenen Ideen sich mit den Vorstellungen von der gegen die Sterne und den Mond kämpfenden Sonne mischen. Insonderheit wird der mit dem Monde in Verbindung stehende Vegetationswechsel zu der Sonne in Beziehung gesetzt, indem die nächtlichen Götter als Sonnengottheiten während des Sommers auftreten und im Winter wieder zu ihrem Stern. himmel zurückkehren. Utber allem aber steht der Gedanke, daB sie Schöpfergötter sind, also die Welt verkörpern und daher keineswegs mit der Bezeichnung Mondgott, Morgenstern, Sonne u. dgl. in ihrem Wesen erschöpft sind. Sie entlehnen nur diesen Naturdingen Schicksalszüge.

\section{Botokuden.}

Ein glücklicher Zufall hat es gefügt, daß wir neuerdings auch von den auf besonders niedriger Kulturstufe stehenden Botokuden einen höchsten Gott kennen, den alle früheren Forscher kaum erwähnen ${ }^{1}$ ). Obwohl keine Texte über ihn vorliegen und das Gesamtbild der Religion dieses Stammes unvollständig ist, dürfen wir uns diesen Typus nicht entgehen lassen. Er heißt Maret Khmakniam (= Greis). Seine Gestalt ist über-

1) H. H. Manizer, Los Botocudos d'après les observations recueillies pendant un séjour chez eux en 1915. Archivos do Museu Nacional XXII, Rio de Janeiro 1919. Vgl. Paul Ehrenreich, Über die Botocudos der brasilianischen Provinzen Espiritu Santo und Minas Geraes. Zeitschr. f. Ethnologie 19. Berlin 1887. 
menschlich und etwa eine Hand größer wie die der Menschen. Sein Penis ist gewaltig groß. Sein Kopf ist weiß, das Gesicht ganz bis an die Augen mit rotem Tierhaar bedeckt. Er befindet sich im Himmel und hat eine Frau. Ihm gêhören die Sterne, er hat viele Kinder. Die Sonne werde von dem Alten geschickt, ebenso wie die Regierung die Züge schicke, die dort in der Nähe vorbeifahren. Abends tritt sie in den Himmel ein und verweilt bei Maret, dem Alten, des morgens verabschiedet sie sich von ihm, um ihren Platz am Horizont im Osten einzunehmen. Wenn kein Mond am Himmel ist, so weilt er bei Maret. Bei den Mondphasen bedeckt er ihn. Der Mond sei wie eine Blechkanne, in der Petroleum oder dergleichen brennt. Maret geht auf den Wolken und im Wasser und schickt Regen und Ungewitter. Er hat kein Schuhzeug, aber weder abgestürzte Zweige der Bäume noch Dornen vermögen ihn zu verletzen. Sein Messer ist lang wie ein Bogen: damit kann er Bäume umschlagen. Er versteht es, Pfeile zu machen.

Wenn jemand ihn erzürnt, so trifft er ihn mit einem unsichtbaren Pfeil direkt ins Herz. Die Burung, d. h. Menschen, wie die Botokuden sich selbst nennen, liebt er und ist erzürnt, wenn jemand, z. B. die Brasilianer, sie übel behandelt. Die Burung stehen daher mit ihm auf gutem Fuße und wollten sich dem Beobachter Manizer und dessen Leuten gegenüber mit ihm wichtig tun und sie einschüchtern, indemı man ihn rufen wollte. Sie erwarteten Marets Besuch und wollten andererseits die Besucher schützen und benachrichtigen, damit diese dann nicht über den Fluß gingen, und sie wollten sich auch Mühe geben, daß jener wieder in die Tiefe der Wälder zurückkehre. Man sprach auch von dem Erscheinen der Kinder dieses Wesens.

Er erfreue sich an getrocknetem Fleisch und Reis, den Geschenken der Regierung. Er habe nicht genug Mandiocamehl, Bohnen und Wildpret, das die Burung selbst gewinnen. Manizer wurde empfohlen, er solle ihm Reis bringen. Den esse er in der Nacht. Wenn er es nicht tue, so würde Maret ihn seiner Frau zum Gespött ausliefern, und er müsse mit ihr schlafen. Vor einem Gewitter ruft man ihn an: ,Erzürne dich nicht, Maret, " und sie stoßen bei starkem Gewitter Schreie aus und bitten ihn, sie nicht zu töten. Dann schießen sie in höchster Erregung Pfeile mit entzündeten Halmen oder mit Wachs an der Spitze ab. Bei nächtlichen Tänzen sollen sie singen: „Töte die Bösewichter." Bei öfterem Gesang kommt er und streut im Walde Rollentabak und eiserne Werkzeuge für die Burung aus.

Dieser Gott trägt die unverkennbaren Züge eines höchsten Wesens, obwohl ihm weder eine Welt- und Menschenschöpfung noch die Verleihung des Kults an die Menschen nachgesagt wird. Doch genügt als Ersatz für das letztere schon die Angabe, der Gebrauch der Lippenpflöcke sei der Wille Marets, und sie dürften daher nicht entfernt werden. 
Er herrscht über die Welt, ist gütig und gerecht und erhält sie, indem er den Tod dem gibt, der ihn erzürnt, was wohl nur eine Umschreibung der Weltordnung ist, indem die Unvollkommenheit, die den Tod herbei führt, als Schuld erscheint. Mit einer Verkörperung eines Naturdinges, des Unwetters und der Wolken, als Blitz hat der unsichtbare Pfeil nichts zu tun. Doch tötet er auch durch den Blitz und gilt dann als erzürnt In dieser Eigenschaft wird er auch kultisch behandelt, da wir annehmen müssen, daß die brennenden Pfeile als Analogiezauber den Blitz lenken. Auch eine frühere Quelle berichtet, daß bei einem Gewitter Pfeile in die Luft geschossen werden mit dem Rufe: „Der große Häuptling zürnt.“ Auf diesem Wege ist es auch möglich, daß er Opfergaben an Nahrung erhält. Indessen sind überhaupt direkte Beziehungen zu ihm, die sich auch in den Tänzen und Anrufungen ausdrücken, festzustellen, obwohl sie dem höchsten Wesen ursprünglich fremd sind.

Im Gegensatz zu dem Vertrauen der Burung zu ihrem höchsten Wesen steht die Furcht vor den Verstorbenen nanitiong. Sieht man einen im Wachen oder im Traum, so bedeutet das den Tod der betreffenden Person. Als jemand berichtete, er habe auf dem jenseitigen Flußufer einen nanitiong gesehen, herrschte allgemeine Panik. Es wurden Flinten abgeschossen, und man sang und tanzte die ganze Nacht. Deshalb läßt man den Toten in der Hütte und verläßt den Ort. Bisweilen schleppt man ihn auch in den Wald und zieht fort.

So verschiedenartig auch die Gestalten sind, die wir unter dem Begriff einer höchsten Gottheit kennen gelernt haben, so lehren sie doch eins, da $B$ die Religion in der Hauptsache von zwei entgegengesetzten und doch einander beeinflussenden Polen ausgeht: den Beziehungen des Menschen zu einem höchsten, die Welt beherrschenden Wesen einerseits und zu wirkend oder lebendig gedachten einzelnen Naturdingen andererseits, denen sich die Verstorbenen hinzugesellen. Beides geht von jeher nebeneinander her, ohne daß ein Vorrang oder geschichtliches Vorausgehen festzustellen ist. Die Idee einer höchsten Gottheit ist nicht schwerer zu begreifen wie die der mehr oder weniger lebendigen Naturdinge. Beide Gedanken beruhen auf demselben Denkvorgang, den wir als Verkörperung der Welt bzw. der einzelnen Naturdinge beschreiben. Erstere ist die Welt, schafft und erhält sie durch den Kult, den sie den Menschen gegenüber den Naturdingen gibt, dessen Weltgesetze aber in dem höchsten Wesen selbst verkörpert sind. $\mathrm{Zu}$ dem Kult in weiterem Sinne gehören aber auch zauberische Handlungen ohne Beziehung auf ein Naturding, Gebräuche, die für Wohlergehen und Gelingen notwendig erscheinen, und durch deren Verkörperung Wesen als Beschützer von Tätigkeiten 
u. dgl, m. entstehen können. Auch das besteht von jeher neben dem andern, ohne der Anfang zu sein.

Eine Entwickelung der Religion geht im wesentlichen nur auf dem Wege des Naturerkennens vor sich. Deshalb stehen wir dem Begriff der Verkörperung einer wirkenden Kraft, die den Kulturarmen geläufig war, uns aber philosophisch anmutet, besonders verständnislos gegenüber. $\mathrm{Um}$ sie $\mathrm{zu}$ begreifen, nahmen viele Forscher ihre Zuflucht zu unsern Anschauungen von Geist und Materie und glaubten etwas Ähnliches in dem Seelenbegriff gegenüber dem Körper zu finden. In Wirklichkeit besteht aber der Gegensatz zwischen Körperlichem und Geistigem bei den Kulturarmen nicht, und auch die Seele des Menschen ist ihnen immer stofflich, ebenso wie Kraft und Stoff sich bei ihnen nicht unterscheiden läßt. $\mathrm{Ob}$ ein Stamm also ein Wort für Seele hat oder nur von Verstorbenen, Toten redet, ist für die Religion gleichgültig. Der Tote oder die Seele ist vielmehr nur als eine besondere Art Naturding anzusehen.

Dagegen ist uns der Begriff eines höchsten Gottes, da er unserem Naturerkennen unzugänglich erscheint, noch heute so geläufig, daß wir diesen Gedanken, der von jeher als eine Verkörperung der Welt besteht, den Kulturarmen absprechen zu müssen glaubten. Und doch dürfte es keine Religion geben, wo nicht die im Menschen beständig wirkende Vorstellung einer Weltschöpfung und Welterhaltung lebendig ist und zur Gestaltung der Religion beiträgt. Denn nicht die starre, weltenferne Gottheit, die sich nicht direkt um die Menschen kümmert und von ihnen keinen Kult genießt, ist das Gewöhnliche, sondern ihre Verbindung mit einem oder mehreren Naturdingen. Dadurch werden diese in das Wesen der höchsten Gottheit hineingezogen und der ihnen gewidmete Kult auf die Gottheit übertragen, während sie selbst, die ursprünglich feindlich waren und durch den Kult gelenkt werden mußten, etwas von dem gesetzlichen, gerechten, gütigen des Weltschöpfers und -erhalters annahmen. Auch auf die andern Naturdämonen hat dann diese Verbindung vielfach abgefärbt und hat sie zu Göttern erhoben. Neben dem ausschließlich zauberischen Kult trat Gebet und Opfer als fromme Gabe, und das Zauberische selbst wurde zur frommen Handlung. Solche Verbindungen können von vorneherein eingetreten sein, soweit wir die Menschheit überblicken, und das ist nicht weit. Jedenfalls gibt es außerordentlich verschiedene Gestaltungen des Bestehens und Zusammentretens der beiden Pole, und wir müssen beiden Seiten gleichmäßig in geschichtlichem Verfolgen und in psychischer Analyse gerecht werden, dürfen dabei aber nie vergessen, daß geschichtliche Entwickelung und Fortschritt vom vermeintlich Niederen zu Höherem zweierlei ist. 
208 K. Th. Preuß: Die höchste Gottheit bei den kulturarmen Völkern.

Das zweite, was wir vielleicht aus den vorausgehenden Materialien lernen können, ist die Bedeutung des Mythus für die Religion. Erzählungen der Naturvölker sind nicht erkenntnistheoretischer Natur, sondern sind für das Wohlergehen notwendig und daher religiös. Mythologie kann daher nur im engen Anschlu $B$ an die Religionswissenschaft betrieben werden. Noch heute ist es wahrscheinlich, daß der mythische Gehalt von Erzählungen den Kulturarmen vielfach gegenwärtig ist. Wenn z. B. ein höchster Gott nach dem Symbol des Mondentstehens die Welt und die Menschen schafft, so ist der Gott die Verkörperung der Welt und zugleich des Mondes, aber auch der Menschen, die dadurch das Wesen der Gottheit und des Mondes selbst in sich tragen. Sie kommen vielleicht wie aus dem dunkeln Monde aus einem Loch in der Erde, und ihr eigenes menschliches Geschick erzählen sie, wenn sie nach unsern übrigens auch erst seit kurzer Zeit auftauchenden - Anschauungen von Mondwesen und deren Geschick sich unterhalten. Weil uns der strenge Begriff der Verkörperung fehlt, der ihnen geläufig ist, begreifen wir sie nicht. Sprechen sie nun von mythischen Wesen, die mit mythischen Schicksalen der Welt verknüpft sind, so üben sie auf ihr eigenes Wohlergehen einen Zauber aus und sorgen für das Weltgeschehen oder für das Nichteintreten früherer Weltkatastrophen. Solche Erzählungen sind daher dem Kult an die Seite zu setzen. In der Erzählung von Heilbringern z. B. kräftigen sie die Heiligkeit und Wirksamkeit des Kults, der ihnen durch deren Vermittlung gebracht ist. Ist das Verständnis der Mythen geschwunden, so bleibt die fromme Übung bestehen, bis sie als Märchen aus dem Religiösen heraustreten und freiere Gestaltung zulassen.

(Eingegangen am 1. April 1922.) 